\title{
Evaluation of Simulated Winter Precipitation Using WRF-ARW during the ICE-POP 2018 Field Campaign
}

\author{
Kyo-Sun Sunny Lim, ${ }^{a}$ Eun-Chul Chang, ${ }^{\mathrm{b}}$ RuIYu Sun, ${ }^{\mathrm{c}}$ KWONIL Kim, ${ }^{\mathrm{a}}$ \\ FRANCISCO J. TAPIADOR, ${ }^{\mathrm{d}}$ AND GYUWON LEE ${ }^{\mathrm{a}}$ \\ ${ }^{\mathrm{a}}$ School of Earth System Sciences, Kyungpook National University, Daegu, South Korea; ${ }^{\mathrm{b}}$ Department of Atmospheric Science, \\ Kongju National University, Gongju, South Korea; ${ }^{c}$ I.M. Systems Group, Inc., Rockville, and Environmental Modeling Center, \\ National Oceanic and Atmospheric Administration/National Centers for Environmental Prediction, College Park, Maryland; \\ ${ }^{\mathrm{d}}$ Earth and Space Sciences Research Group, Institute of Environmental Sciences, University of Castilla-La Mancha, \\ Toledo, Spain
}

(Manuscript received 6 December 2019, in final form 17 August 2020)

\begin{abstract}
This study evaluates the performance of several cloud microphysics parameterizations in simulating surface precipitation for two snowstorm cases during the International Collaborative Experiment held at the PyeongChang 2018 Olympics and Winter Paralympic Games (ICE-POP 2018) field campaign. We compared four different schemes in the Weather Research and Forecasting (WRF) Model, namely the double-moment 6-class (WDM6), the WRF singlemoment 6-class (WSM6), and Thompson and Morrison parameterizations. Both WSM6 and WDM6 overestimated the precipitation amount for the shallow precipitation system because of the substantial amount of cloud ice, mostly generated by the deposition process. The simulated precipitation amount and distribution for the deep precipitation system showed no noticeable differences in the different cloud microphysics parameterizations. However, the simulated hydrometeor type at the surface using WSM6 and WDM6 showed good agreement with observations for all cases. The accuracy of the mean mass-weighted terminal velocity of cloud ice $\overline{V_{I}}$ applied in WSM6 and WDM6 is $\pm 20 \%$. The number concentration of cloud ice and the ice microphysics processes are newly retrieved with 1.2 times increased $\overline{V_{I}}$. For the shallow snowstorm, the precipitation amount was reduced by approximately $8 \%$ because of the inefficient deposition and its effects on the subsequent ice microphysical processes, such as the accretion of cloud ice by snow and the conversion from cloud ice to snow.
\end{abstract}

KEYWORDS: Snowfall; Cloud parameterizations; Cloud microphysics

\section{Introduction}

Snowfall over the Korean Peninsula is often formed because of migratory extratropical cyclones or the expansion of the Siberian high (Cheong et al. 2006). When the Siberian high expands into the Manchuria, locally, high pressure is formed over the northern mountainous region of the Korean Peninsula (i.e., the Gaema Plateau). The high pressure system induces northeasterly flows in the lower level over the East Sea, delivering cold air mass into the relatively warm sea surface. Yeo and Chang (2018) revealed that this type of air mass transformation leads to strong thermal instability over the sea, which forms stratocumulus-containing snow. When these snow clouds are transported into the coastal region, the upward motion is induced by the topography (i.e., Taebaek Mountains), and the land-sea temperature contrast triggers heavy snowfall on the coastal region and upslope of the mountains. This mechanism is known as the lake-effect snowfall (Laird et al. 2003), which frequently occurs over the Great Lakes region.

The International Collaborative Experiments for the International Collaborative Experiment held during the PyeongChang 2018 Olympics and Winter Paralympic Games (ICE-POP 2018) field campaign were conducted over the mideastern region of the Korean Peninsula. The purpose of this field

Corresponding author: Eun-Chul Chang, echang@kongju.ac.kr campaign was to obtain various observational datasets in higher spatial and temporal resolutions. These observational datasets could provide insight into cloud microphysics processes and detailed structures of the snow formation. Understanding the snowfall mechanism improves the accuracy of the forecast and enhances the performance of atmospheric models in capturing the winter precipitation over the complex, mountainous terrain. The cloud microphysics parameterization is critical in simulating snowfall in the model, producing grid-resolvable precipitation. To improve the forecast capabilities of the model, the evaluation of currently operating microphysics schemes is required. The ICE-POP 2018 field campaign provides crucial hydrometeor properties, which are rarely acquired during operational observations. Such cloud properties can be used to evaluate the performance of cloud microphysics parameterizations.

Weather Research and Forecasting (WRF) double-moment 6-class (WDM6) (Lim and Hong 2010) and WRF singlemoment 6-class (WSM6) (Hong and Lim 2006) cloud microphysics parameterizations have been widely evaluated for summer precipitation events over the Korean Peninsula (Hong et al. 2010; Min et al. 2015; Song and Sohn 2018), excluding winter precipitation events. These two parameterizations share the same ice microphysics process, which is based on the work by Hong et al. (2004), who introduced a new diagnosis of ice number concentration that depends on the cloud ice mass. Meanwhile, the number concentration of cloud ice is predicted 
based on various cloud microphysics processes, such as accretion, deposition, and freezing in both Thompson (Thompson et al. 2008) and Morrison (Morrison et al. 2005) cloud microphysics parameterizations.

Previous studies reported positive bias in simulating winter precipitation using WSM6 and WDM6. McMillen and Steenburgh (2015) showed that WDM6 resulted in a large overprediction of surface precipitation relative to observations in the simulation of the lake-effect snowstorm on 27 October 2010 because of the excessive amount of graupel. They also noted that graupel and snow production could significantly influence precipitation efficiency in lake-effect storm simulations. Liu et al. (2011) crafted a highresolution regional climate model to evaluate the sensitivity of cold-season mountainous snowfall to the cloud microphysics scheme. Their study revealed that the WSM6 and WDM6 overpredicted the daily amount of precipitation during the 3-month integration.

Several studies reported more cloud ice and graupel and less snow in WDM6 or WSM6, compared to other microphysics schemes, when simulating winter precipitation (e.g., Comin et al. 2018; Morrison et al. 2015; Han et al. 2013). Comin et al. (2018) demonstrated that the WDM6 scheme produced the highest cloud ice mixing ratio among the various schemes (e.g., WSM6, Goddard, Morrison, NSSL, WDM5, WDM6, and WSM3) for the extreme snowfall events in the Southern Andes. Morrison et al. (2015) also reported that WDM6 and WSM6 produced large amounts of cloud ice and graupel relative to snow in the winter orographic precipitation case during the second Improvement of Microphysical Parameterization through Observational Verification Experiment (IMPROVE)-2 field experiment.

Our study aims to evaluate the cloud microphysics parameterizations (WDM6, WSM6, Thompson, and Morrison), especially the simulated surface precipitation amount and hydrometeor type at the surface during the ICE-POP 2018 field campaign over the Korean Peninsula. We also investigate the mechanism that generates cloud ice and its subsequent effect on surface precipitation, along with a detailed microphysics budget analysis. Although previous studies revealed that WDM6 and WSM6 generate larger amounts of cloud ice than other schemes, there have been no investigations on the effect of cloud ice production on surface precipitation efficiency under the different precipitation systems. Even though diagnostic precipitation-type postprocessing was developed using the predicted hydrometeor information from the Thompson microphysics scheme (Ikeda et al. 2013; Benjamin et al. 2016) and intensively evaluated with surface precipitation-type observations over the United States (Burg et al. 2017), the simulated hydrometeor information at the surface has not been compared with observations in any other study during the winter season in Korea.

Section 2 explains the selected snowstorm cases. In sections 3 and 4 , we present the experimental setup and results. In the final section, we summarize and discuss the results.

\section{Case description}

There were eight snowfall events during the ICE-POP 2018 field campaign period. We selected two of these snowfalls to evaluate the cloud microphysics parameterizations, namely 15-16 March 2018 (CASE1) and 4-5 March 2018 (CASE2). Figure 1 depicts surface weather charts and accumulated precipitation in the automatic weather station (AWS). The precipitation amount measured in the AWS is contributed by all types of hydrometeors. Both CASE1 and CASE2 show that the high pressure system over the Gaema Plateau (see Fig. 2a), which induces northeasterly winds over the East Sea, affects the Korean Peninsula. During both periods, the air temperature at $925 \mathrm{hPa}$ and the sea surface temperature near the eastern coast region are $-10^{\circ}$ and $10^{\circ} \mathrm{C}$, respectively. A temperature difference of approximately $20^{\circ} \mathrm{C}$ in $1-\mathrm{km}$ height displacement has a lapse rate of $2 \mathrm{~K}(100 \mathrm{~m})^{-1}$, indicating that it is much more unstable than the lapse rate of the standard atmosphere [i.e., $0.6 \mathrm{~K}(100 \mathrm{~m})^{-1}$ ]. Such thermal instability induces strong updrafts, and large temperature differences lead to moisture transporting from the sea surface to the atmosphere in the form of latent heat flux.

One major difference between the two cases is the role of the synoptic low system. In CASE2, the low system passes closer to the Korean Peninsula than in CASE1. This leads to a stronger pressure gradient over the East Sea, producing stronger wind speeds in CASE2. The stronger horizontal wind speed is favorable for the lake-effect snowfall type, resulting in a larger amount of snowfall. Note that the observed precipitation amount is larger in CASE2 (see Figs. 1c,d). However, when the low system moves away from the Korean Peninsula, the rear side of the low pressure induces northerly or northwesterly flows over the East Sea, interrupting the inflow of the snowfall into the Korean Peninsula. With or without the low pressure system, the high pressure on the Gaema Plateau is stationary because it is formed by the topography. Without the low pressure system, the northeasterly by the Gaema high pressure system is also stationary, leading to persistent snowfall on the eastern part of the Korean Peninsula. Consequently, because of the low pressure system, which could intensify the snowfall in CASE2, the duration of the snowfall in CASE2 is shorter than in CASE1; however, the total snowfall amount in CASE2 is larger than in CASE1.

\section{Experimental setup}

\section{a. Model configuration}

In this research, we employed the Advanced Research version of WRF, version 4.0 (ARW; Skamarock et al. 2008), which is often used for research and forecasting areas over the Korean Peninsula (Byun et al. 2015; Lim et al. 2019), and research on winter storms all over the world (Campbell et al. 2018; Comin et al. 2018; Conrick and Mass 2019). The WRF Model is a fully compressible, nonhydrostatic model with an Arakawa-C grid system and several options for each physics parameterization. The chosen physics package included the unified Noah land surface scheme (Chen and Dudhia 2001), the Rapid Radiative Transfer Model for General Circulation Models (RRTMG) longwave and shortwave radiation scheme (Iacono et al. 2008; Morcrette et al. 2008), the Yonsei University planetary boundary layer scheme (Hong et al. 2006), and the Kain-Fritsch (KF) (Kain 2004; 
(a)

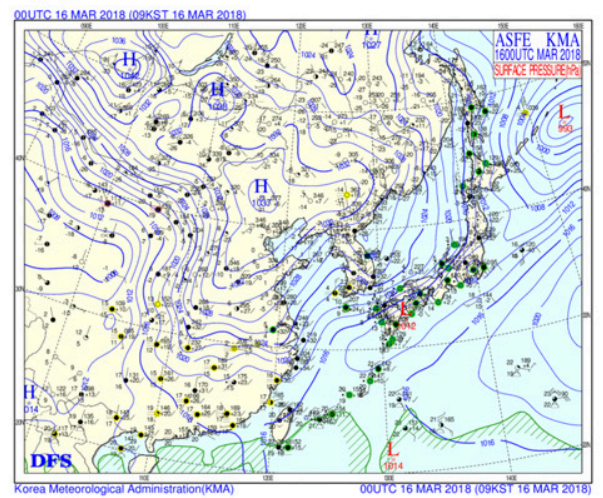

(c)

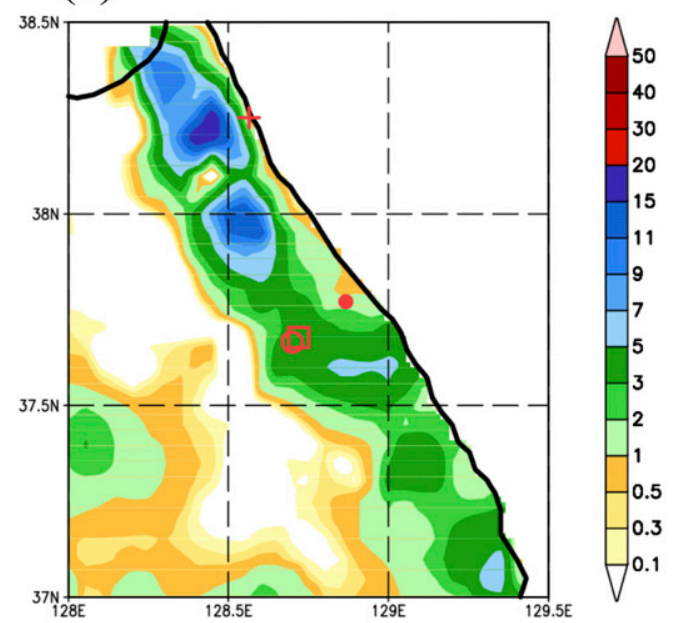

(b)

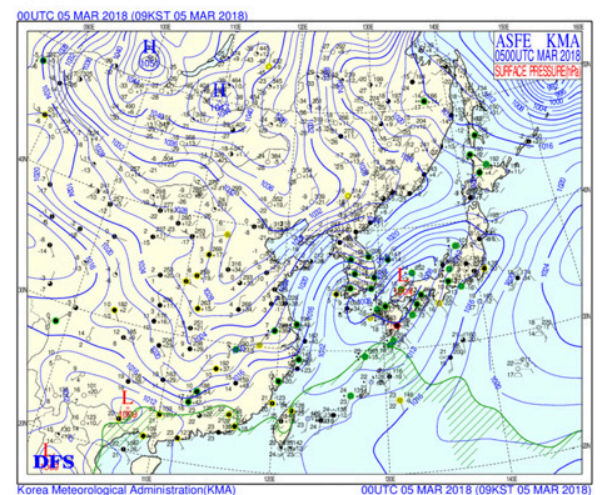

(d)

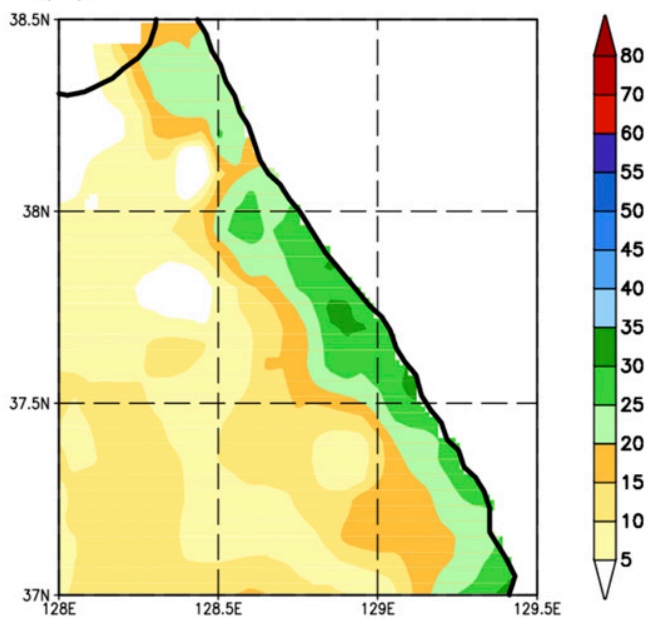

FIG. 1. The Korea Meteorological Administration (KMA) surface chart for (a) 0000 UTC 16 Mar 2018 (CASE1) and (b) 0000 UTC 5 Mar 2018 (CASE2). The KMA surface chart includes the information of weather observations at the surface, including wind field, presence of precipitation, and pressure. The interval of the isobars, drawn in a contour line for (a) and (b), is $2 \mathrm{hPa}$. Accumulated precipitation $(\mathrm{mm})$ obtained from the Automatic Weather Station (AWS) observation for (c) CASE 1 for $17 \mathrm{~h}$ from 1300 UTC 15 Mar to 0600 UTC 16 Mar, and (d) CASE 2 for $9 \mathrm{~h}$ from 1500 UTC 4 Mar to 0000 UTC 5 Mar 2018. The red marks in (c) indicate the Parsivel measurement sites. Cross and dot marks represent the location of coastal sites (SCW and GWU), and open square and circle marks are mountain sites (DGW and MHS).

Kain and Fritsch 1990). The cumulus parameterization was only applied to the outer domain of a 9-km resolution grid.

Four different cloud microphysics parameterization schemes, namely WSM6, WDM6, Thompson, and Morrison, were chosen to examine the impact of the selected parameterizations on the simulated winter precipitation. All four microphysics parameterizations have five hydrometeors, namely cloud water, rain, cloud ice, snow, and graupel with water vapor. WSM6 and WDM6 share the ice microphysics processes based on Hong et al. (2004). The mass of cloud ice in both parameterizations influences the diagnosis of the number concentration of cloud ice (see the appendix). WSM6 only predicts mixing ratios for all hydrometeors. Meanwhile, WDM6 was developed by adding the number concentrations for warm-phase physics to WSM6 (Lim and Hong 2010). Thompson predicts the number concentration and mixing ratio of cloud ice and rain but predicts only the mixing ratio for other hydrometeors. Meanwhile, Morrison treats hydrometeors with the double-moment approach, except for cloud water, thus simultaneously predicting the mixing ratio and number concentration. In the aerosol-aware version of Morrison, cloud water can be also treated as a doublemoment approach. The deposition of water vapor to cloud ice, the nucleation of cloud ice, and cloud water freezing are the major processes to generate cloud ice in four schemes. Thompson and Morrison have the ice multiplication process, which is absent in WDM6 and WSM6.

WDM6 has been updated several times since the work by Lim and Hong (2010) from the process of raindrop evaporation to cloud condensation nuclei. This process parameterizes the situation where the whole amount of rain mass is evaporated, thus converting the rain number concentrations 

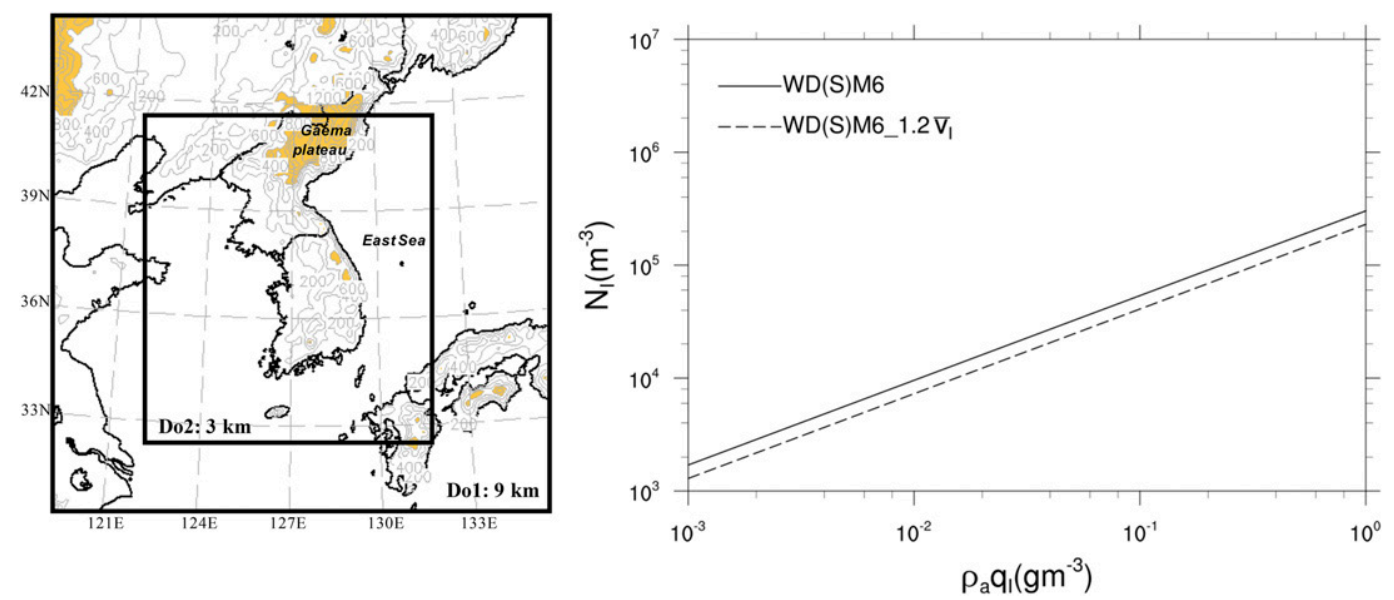

FIG. 2. (a) Model domain configuration with terrain contoured every $200 \mathrm{~m}$ for the 9 -km resolution grid (Do1). The resolution of the inner domain (Do2) is $3 \mathrm{~km}$. The terrain height greater than $800 \mathrm{~m}$ is shaded. (b) Number concentration of cloud ice $N_{I}$ with varying cloud ice amount $\rho_{a} q_{I}$ in WD(S)M6 (solid line) and WD(S)M6_1.2 $\overline{V_{I}}$ (dashed line).

into the number of cloud condensation nuclei. The minimum values for the slope parameter of raindrop and cloud droplet size distributions were also introduced to prevent unrealistic size distribution. Last, the effective radii of hydrometeors calculated in WDM6 were linked with the Rapid Radiative Transfer Model for GCMs (RRTMG) scheme to consider the cloud effects in radiative flux calculations (Bae et al. 2016).

The initial and boundary conditions were forced every six hours by the European Reanalysis (ERA) Interim produced by ECMWF (Dee et al. 2011). The numerical experiments were conducted for $48 \mathrm{~h}$ in both cases. The model integration began at 0000 UTC 15 March 2018 for CASE1 and at 0000 UTC 3 March 2018 for CASE2. The model configuration consisted of a nested domain defined on a Lambert conformal projection (Fig. 2a). A 3-km resolution model domain covering the Republic of Korea was surrounded by a 9-km grid model domain. A one-way interaction was applied in the integrations. We set the number of vertical layers as 40 . The simulated precipitation was evaluated over the Yeongdong area of northwestern South Korea, which is the same area shown in Figs. 1c and 1d.

\section{b. Sensitivity experiment}

Heymsfield and Donner (1990) noted that the accuracy of the mean mass-weighted terminal velocity of cloud ice $\overline{V_{I}}$, parameterized based on mixing ratio of cloud ice, is $\pm 20 \%$. This uncertainty of $\overline{V_{I}}$ would affect certain cloud ice characteristics such as cloud ice number concentration $\left(N_{I}\right)$ and mixing ratio of cloud ice $\left(q_{I}\right)$ in WDM6 and WSM6. The sensitivity experiment in which $\overline{V_{I}}$ experienced a 1.2-times increase relative to its original value was conducted to examine the impact of the uncertainty in $\overline{V_{I}}$ on the simulated cloud ice and surface precipitation. With a 1.2-times increase in $\overline{V_{I}}$, the properties of cloud ice such as $N_{I}$ and $q_{I}$ can be written as Eqs. (1), (2a), and (2b). The original ones in WDM6 and WSM6 can be found in Eqs. (A5), (A6a), and (A6b) of the appendix with a detailed derivation:

$$
\begin{aligned}
N_{I}\left(\mathrm{~m}^{-3}\right) & =4.09 \times 10^{7}\left(\rho_{a} q_{I}\right)^{0.75}, \\
\rho_{a} q_{I}\left(\mathrm{~kg} \mathrm{~m}^{-3}\right) & =6.58 \times 10^{-11} N_{I}^{1.33}, \\
& =0.87 \times 10^{22} D_{I}^{8} .
\end{aligned}
$$

As $\overline{V_{I}}$ increases, $N_{I}$ decreases [see Eqs. (1) and (A5)]. The velocity $\overline{V_{I}}$ directly affects the sedimentation of cloud ice and cloud microphysics processes. The sensitivity experiments were conducted using both WDM6 and WSM6. The experiments are titled WDM6_1.2 $\overline{V_{I}}$ and WSM6_1.2 $\overline{V_{I}}$. Figure 2b shows that the diagnosed $N_{I}$ in WD(S)M6_1.2 $\overline{V_{I}}$ is less than in $\mathrm{WD}(\mathrm{S}) \mathrm{M} 6$ at a given cloud ice amount $\rho_{a} q_{I}$.

\section{Results}

\section{a. Comparison of microphysics parameterizations} for CASE1

Figure 3 presents simulated precipitation using WDM6, WSM6, Thompson, and Morrison. With WDM6 and WSM6, the overestimation of the precipitation is apparent along the eastern part of the analysis domain where the region is characterized by complex, mountainous areas (Figs. 2 and 3). The simulation with Morrison produces the least amount of surface precipitation of all the simulations (Table 1) and shows the best agreement with the AWS observation regarding bias and rootmean-square error (RMSE). The simulations with WDM6, WSM6, and Thompson reveal that most of the surface precipitation is comprised of solid-type hydrometeors (snow, cloud ice, and predominately graupel), whereas Morrison produces fewer solid-type hydrometeors at the surface than the other microphysics schemes, resulting in the reduction of surface precipitation (Figs. 3e-h). Furthermore, the rain regions using Thompson and Morrison propagate toward mountains, 
(a) WDM6

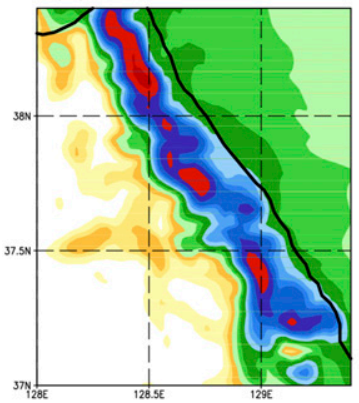

(e) WDM6

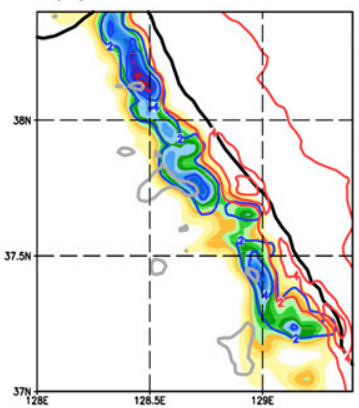

(b) WSM6

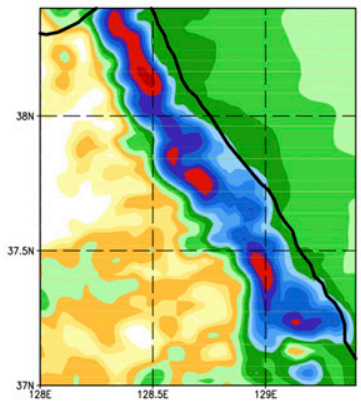

(f) WSM6

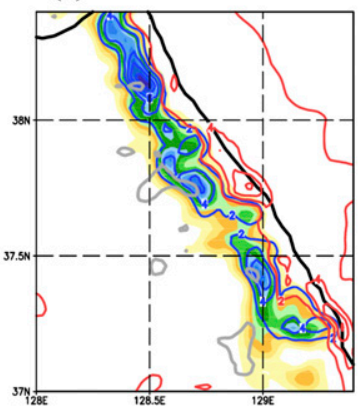

(c) Thompson

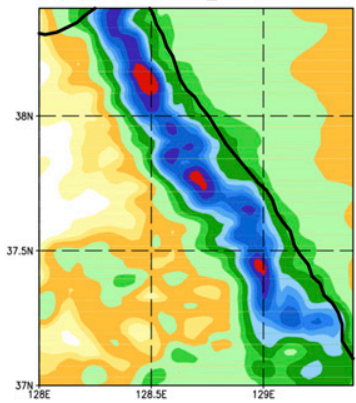

(g) Thompson

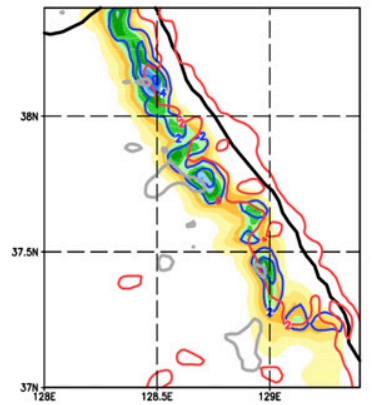

(d) Morrison

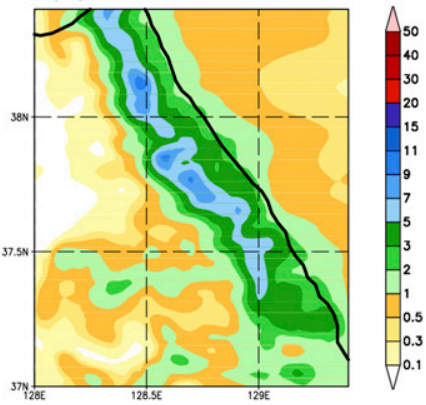

(h) Morrison

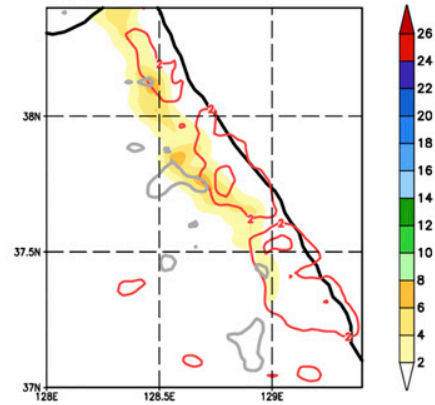

FIG. 3. (a)-(d) Simulated precipitation ( $\mathrm{mm}$ ) using different cloud microphysics parameterizations for CASE1 for $17 \mathrm{~h}$ from $1300 \mathrm{UTC}$ 15 Mar to 0600 UTC 16 Mar. (e),(f) The simulated precipitation ( $\mathrm{mm}$ ) contributed from snow and falling ice (color shaded), graupel (blue contoured), and rain (red contoured) at the surface. The contour interval for graupel and rain is $2 \mathrm{~mm}$, and the terrain height greater than $1 \mathrm{~km}$ is drawn with thick gray lines in (e) and (f).

whereas those of WDM6 and WSM6 are confined to the coastal areas and eastern slope of mountains.

Simulated hydrometeor types at the surface are compared qualitatively with particle size measurements using Parsivel disdrometers (Löffler-Mang and Joss 2000; Tokay et al. 2014) at the surface (Fig. 4). The frequency distributions of particle fall velocity as functions of diameter show that the two coastal sites observe mostly rain, whereas the two mountain sites show graupel-like fast-falling snow particles. Therefore, a large amount of simulated graupel from WDM6 and WSM6 is more convincing than the rain over the mountains from the Thompson and Morrison simulations.

Figure 5 shows the vertical profiles of the time-averaged hydrometeors. Consistent with the revealed feature in surface precipitation, Morrison rarely produces graupel over the layers and produces significantly less snow and more cloud water. Although WDM6 and WSM6 show different features in the vertical profile of cloud water, which could be caused by the different treatment of warm rain processes in the two schemes (Lim and Hong 2010), both simulations show substantial amounts of cloud ice. To understand which microphysics process is responsible for the abundant generation of cloud ice and the positive bias in surface precipitation, we conducted a microphysics budget analysis with WDM6 and WSM6.

Figure 6 shows the relative contribution of microphysics processes. The production rate of microphysics processes is averaged over the same analysis domain and time duration as in the precipitation and hydrometeors analysis (Figs. 3 and 5).

TABLE 1. Statistical skill scores of bias, pattern correlation (PC), and root-mean-square error (RMSE) for the simulated surface precipitation with a $3-\mathrm{km}$ grid spacing.

\begin{tabular}{|c|c|c|c|c|c|c|c|}
\hline \multicolumn{4}{|c|}{ CASE1 } & \multicolumn{4}{|c|}{ CASE2 } \\
\hline Expt & BIAS & $\mathrm{PC}$ & RMSE & Expt & BIAS & $\mathrm{PC}$ & RMSE \\
\hline Thompson & 2.18 & 0.68 & 4.15 & Thompson & 6.78 & 0.70 & 8.72 \\
\hline Morrison & -0.09 & 0.67 & 1.88 & Morrison & 8.82 & 0.70 & 10.64 \\
\hline WSM6 & 2.97 & 0.67 & 5.60 & WSM6 & 8.24 & 0.73 & 10.07 \\
\hline WDM6 & 2.88 & 0.68 & 5.76 & WDM6 & 6.84 & 0.70 & 9.16 \\
\hline \multicolumn{4}{|c|}{ Sensitivity expt } & \multicolumn{4}{|c|}{ Sensitivity expt } \\
\hline WSM6_1.2 $\overline{V_{I}}$ & 2.56 & 0.67 & 4.76 & WSM6_1.2 $\overline{V_{I}}$ & 8.01 & 0.73 & 9.85 \\
\hline WDM6_1.2 $\overline{V_{I}}$ & 2.53 & 0.68 & 5.07 & WDM6_1.2 $\overline{V_{I}}$ & 6.33 & 0.72 & 8.59 \\
\hline
\end{tabular}


(a) MHS site

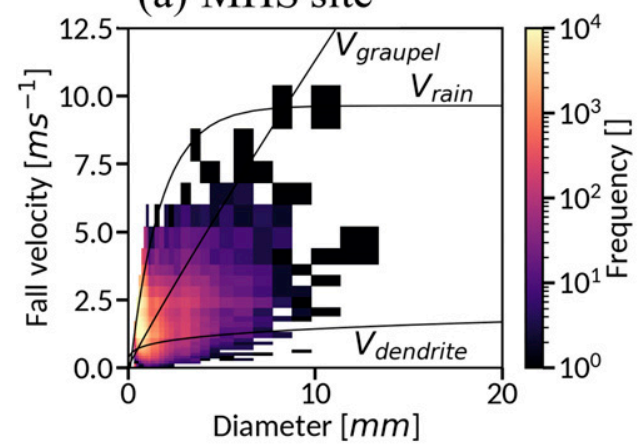

(c) DGW site

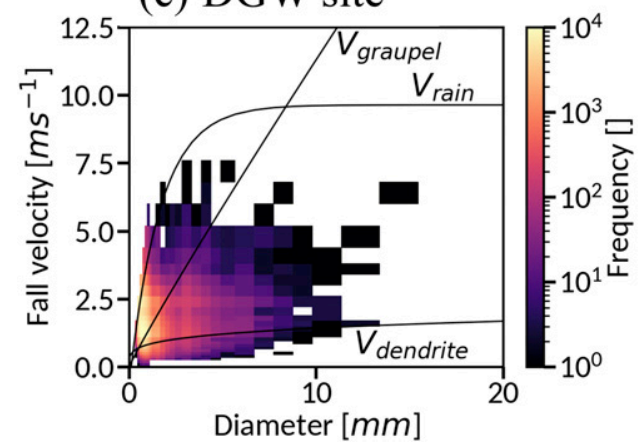

(b) SCW site

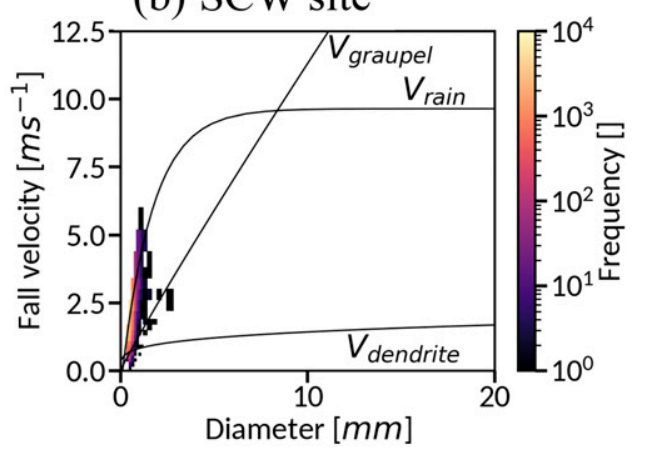

(d) GWU site

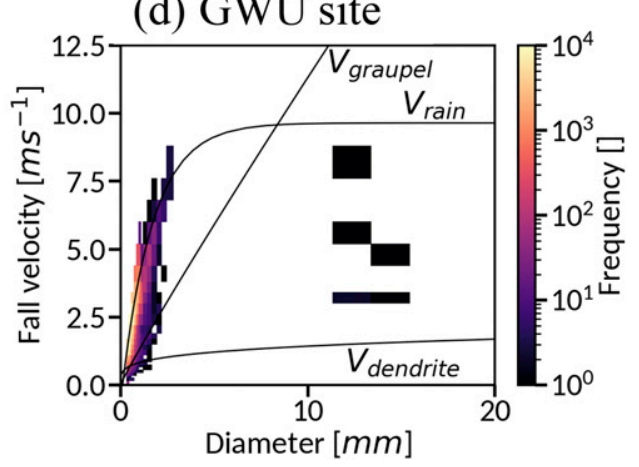

FIG. 4. Frequency distribution of measured particle fall velocity as functions of diameters at (a),(c) two mountain and (b),(d) two coastal sites from 1300 UTC 15 Mar to 0600 UTC 16 Mar 2018. The solid lines indicate the relationships between particle fall velocity and diameters for three hydrometeor types (rain, graupel, and dendrite) at sea level. The fall velocity curve of rain is the power law fit to the Gunn and Kinzer (1949) data (Atlas et al. 1973), and the curves of graupel and dendrite are derived from the observed data (Lee et al. 2015).

The absolute values of every production rate to generate or remove a certain hydrometeor are summed, and each production rate is divided by the sum to generate a percentage. The positive rates indicate the source, and the negative rates indicate the sinking of the hydrometeors. The contribution of sedimentation could be estimated from the hydrometeor mixing ratio and cloud microphysics budget amount.
The upper and lower panels of Fig. 6 show the results of the microphysics budget analysis from WDM6 and WSM6, respectively. Table 2 provides a list of symbols representing microphysical processes. The substantial amount of cloud ice in both simulations is due to the deposition of water vapor to cloud ice (Pidep) (Figs. 6a,f). Most of the snow is shown to be produced by the accretion of cloud ice by snow (Psaci), the (a) WDM6

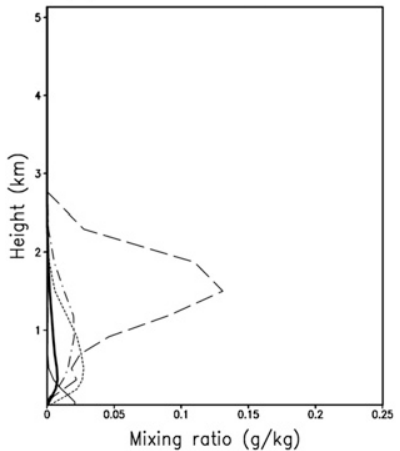

(b) WSM6

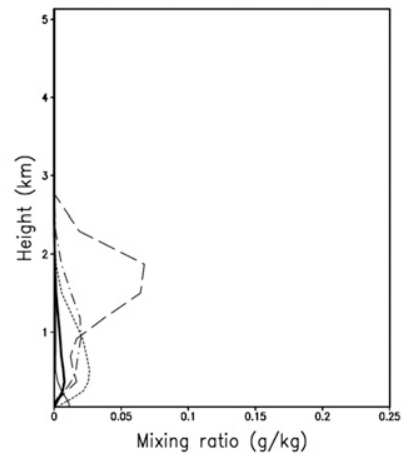

(c) Thompson

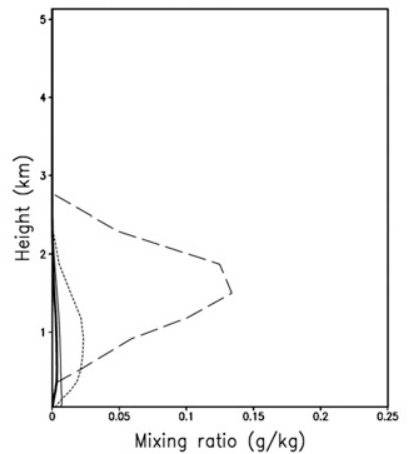

(d) Morrison

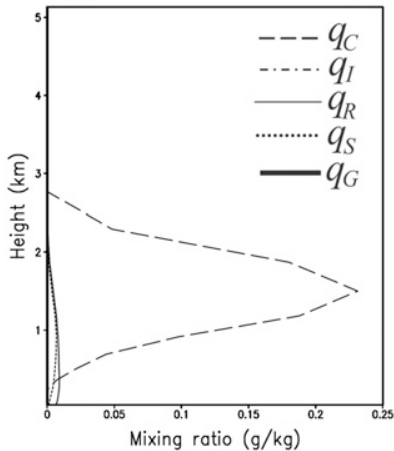

FIG. 5. Vertical profiles of time-domain-averaged mixing ratios of hydrometeors for the experiments using (a) WDM6, (b) WSM6, (c) Thompson, and (d) Morrison. The averaged period and domain are the same as those completed for the simulated precipitation in Fig. 3. 
(a) Cloud ice

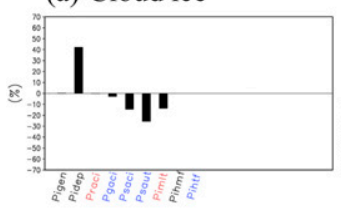

(f) Cloud ice

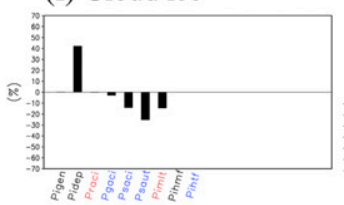

(b) Snow

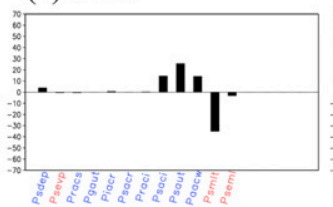

(g) Snow

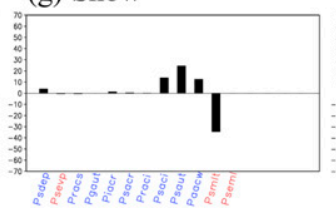

(c) Graupel

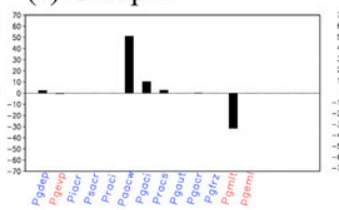

(h) Graupel

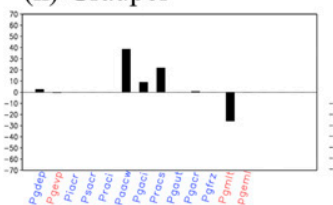

(d) Cloud water

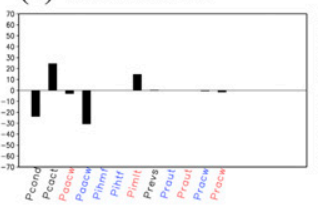

(i) Cloud water

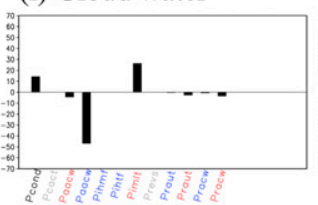

(e) Rain

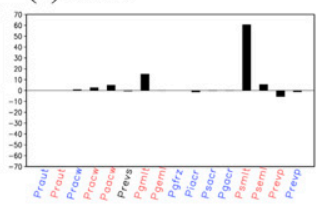

(j) Rain

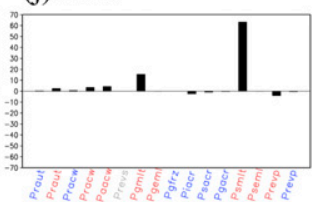

FIG. 6. Relative contribution of production term during the analysis period using the (top) WDM6 and (bottom) WSM6 for (a),(f) cloud ice; (b), (g) snow; (c),(h) graupel; (d),(i) cloud water; and (e),(j) rain. The processes in red (or blue) are activated when the temperature is above (or below) $0^{\circ} \mathrm{C}$. The processes in black are activated regardless of the temperature range. The processes in gray in (i) and (j) represent the nonexistent processes in WSM6.

conversion from cloud ice to snow (Psaut), and the accretion of cloud water by graupel (or snow) (Paacw) (Figs. 6b,g). At the same time, in both simulations, Psaci and Psaut are the main sinks of cloud ice along with its melting from cloud ice into cloud water (Pimlt). Meanwhile, the accretion of cloud ice by graupel (Pgaci) and the accretion of snow by rain (Pracs) with Paacw are responsible for the production of graupel (Figs. 6c,h). Melting is the main sink for graupel and snow that generates most of the rain, while the percentage of Pracs is larger in WSM6 than in WDM6.

For cloud water (Figs. 6d,i), the activation of cloud condensation nuclei (Pcact) and Pimlt are the main sources in WDM6, while cloud water is principally consumed by the evaporation of cloud water (Pcond) and Paacw. Pimlt and Paacw are the main source and sink of cloud water in WSM6. In contrast to the results from WDM6, the condensation of cloud water occurs in WSM6. In the absence of Pcact in WSM6, the surplus water vapor could be condensed to cloud water. In summary, the efficient deposition process in WDM6 and WSM6 generates abundant cloud ice, which, in turn, produces a significant amount of snow and graupel through Psaut, Psaci, and Paacw. Pimlt increases cloud water, which enhances Paacw.

\section{b. Comparison of microphysics parameterizations for CASE2}

The impact of cloud microphysics parameterizations on the simulated surface precipitation and hydrometeors is also evaluated for the deep precipitation system (CASE2). The differences in the precipitation skill scores and the spatial distribution of accumulated precipitation are insignificant as per the choice of cloud microphysics parameterization (Table 1 and Fig. 7). Compared with the AWS observation, the region of peak precipitation is shifted to mountainous areas for most simulations. The WDM6 and WSM6 show a similar amount of surface precipitation to Thompson and Morrison. The pattern correlation (PC) for WDM6 and WSM6 improves compared to CASE 1 (Table 1). Thompson shows the best statistical performance in BIAS and RMSE by producing the least amount of precipitation.

TABLE 2. List of symbols for cloud microphysical processes.

\begin{tabular}{llll}
\hline \hline Process & \multicolumn{1}{c}{ Description } & Process & \multicolumn{1}{c}{ Description } \\
\hline Paacw & Accretion of cloud water by snow/graupel & Pimlt & Instantaneous melting of cloud ice \\
Pcact & Activation of cloud condensation nuclei & Pigen & Generation (nucleation) of cloud ice from vapor \\
Pcond & Condensation/evaporation of cloud water & Praci & Accretion of cloud ice by rain \\
Pgaut & Autoconversion of snow to form graupel & Pracs & Accretion of snow by rain \\
Pgaci & Accretion of cloud ice by graupel & Pracw & Accretion of cloud water by rain \\
Pgacr & Accretion of rain by graupel & Praut & Autoconversion of cloud water \\
Pgdep & Deposition-sublimation rate of graupel & Prevp & Evaporation-condensation rate of rain \\
Pgeml & Enhanced melting rate of graupel & Prevs & Evaporation rate of rain to form cloud water \\
Pgevp & Evaporation of melting graupel & Psaci & Accretion of cloud ice by snow \\
Pgfrz & Freezing of rainwater to graupel & Psacr & Accretion of rain by snow \\
Pgmlt & Melting of graupel to form rain & Psaut & Autoconversion of cloud ice to form snow \\
Piacr & Accretion of rain by cloud ice & Psdep & Deposition-sublimation rate of snow \\
Pidep & Deposition-sublimation rate of ice & Pseml & Enhanced melting rate of snow \\
Pihmf & Homogeneous freezing of cloud water & Psevp & Evaporation of melting snow \\
Pihtf & Heterogeneous freezing of cloud water & Psmlt & Melting of snow to form rain \\
\hline
\end{tabular}


(a) WDM6

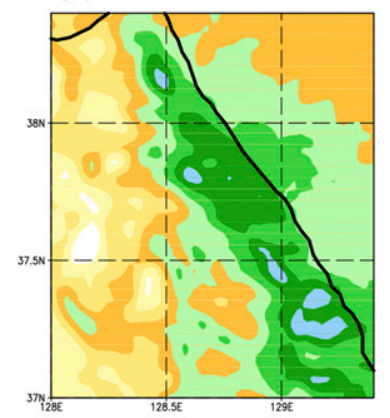

(e) WDM6

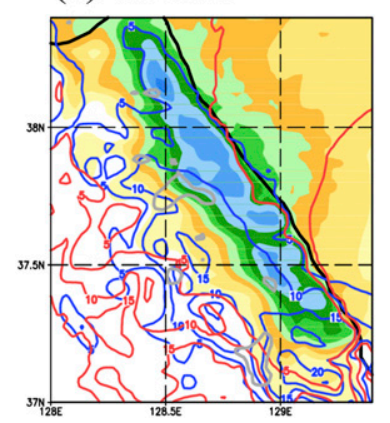

(b) WSM6

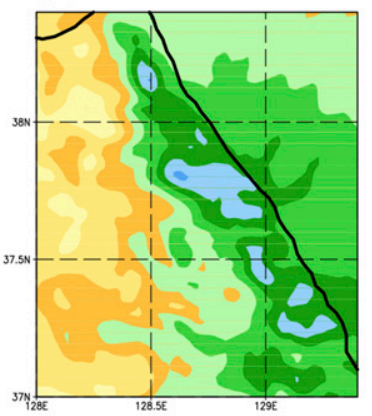

(f) WSM6

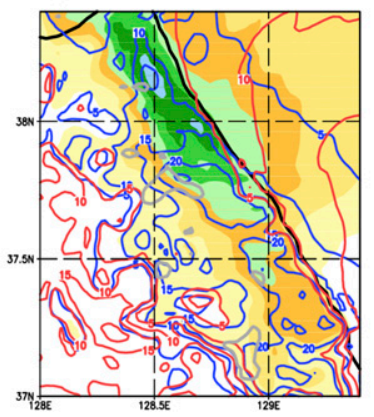

(c) Thompson

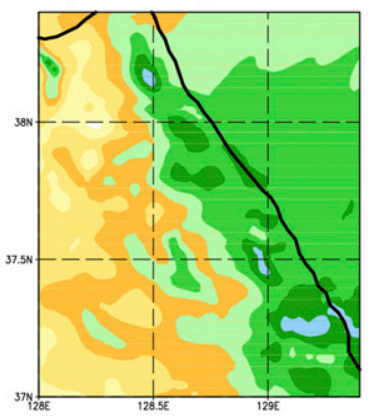

(g) Thompson

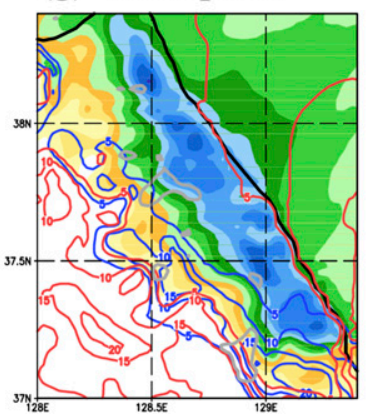

(d) Morrison

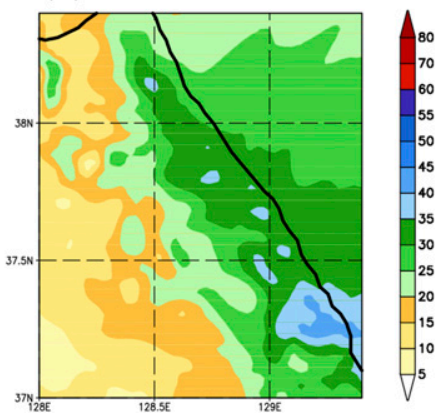

(h) Morrison

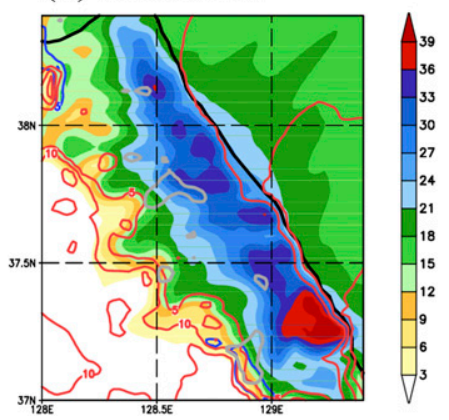

FIG. 7. As in Fig. 3, but representing CASE2, taking place for $9 \mathrm{~h}$ from $1500 \mathrm{UTC} 4 \mathrm{Mar}$ to $0000 \mathrm{UTC} 5 \mathrm{Mar}$.

Rain appears along the coastal line and the southwestern side of the mountains in all simulations. WDM6 and WSM6 produce more graupel and less snow at the surface compared to Thompson and Morrison (Figs. 7e-h). More graupel is simulated over the mountainous areas with WSM6 than with WDM6. No discernible graupel is found over the mountains in the Thompson and Morrison simulations. The vertical profiles of time- and space-averaged hydrometeors also reveal that WDM6 and WSM6 simulate more graupel and less snow than other simulations (Fig. 8). Notably, Morrison does not produce graupel, whereas WDM6 and WSM6 produce a substantial amount of cloud ice and reduced cloud water, supporting the results of CASE1. Morrison only produces cloud ice over the upper troposphere, and Thompson generates little cloud ice.

The frequency distributions of measured particles present two modes at the coastal sites: high-velocity rain mode and low-velocity snow mode (Fig. 9). These are consistent with rain and snow being mixed at the coastal sites from all simulations. High-fall-velocity graupel-like particles are dominant at the mountain sites throughout the study period, as shown in the simulation of WDM6 and WSM6.

Moreover, we conducted a microphysics budget analysis for CASE 2 (Fig. 10). Pidep is still a major production process for (a) WDM6

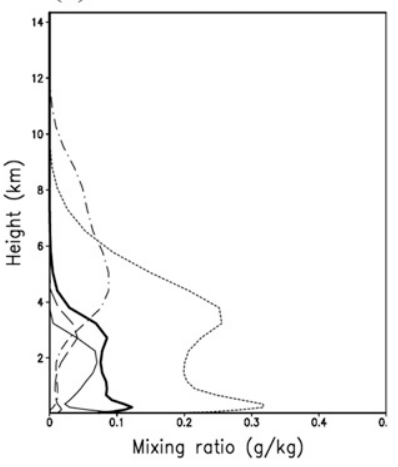

(b) WSM6

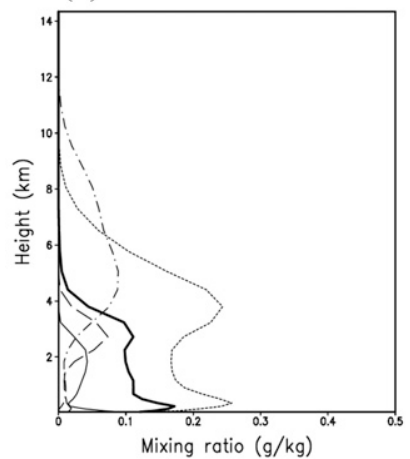

(c) Thompson

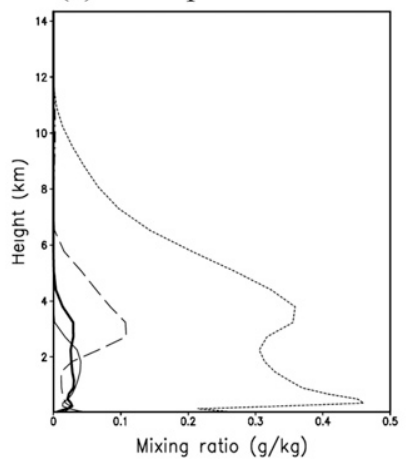

(d) Morrison

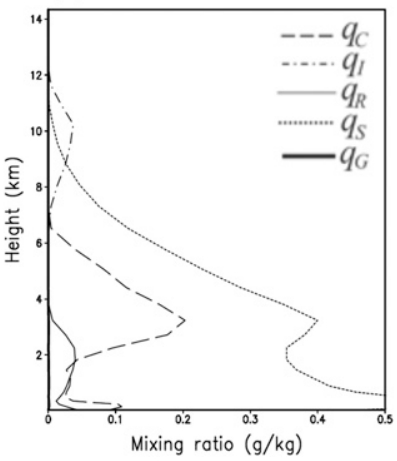

FIG. 8. As in Fig. 5, but representing CASE2. 
(a) MHS site

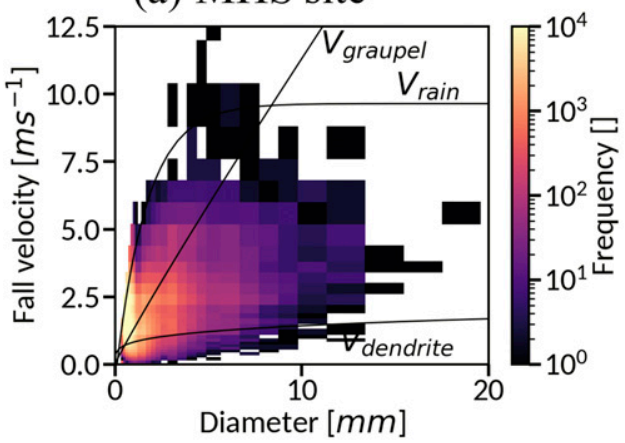

(c) DGW site

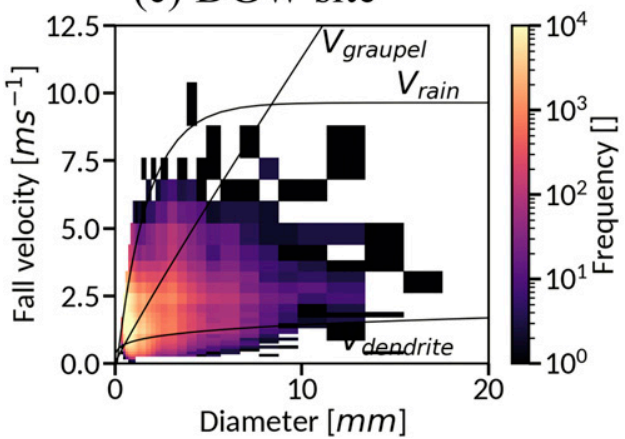

(b) SCW site

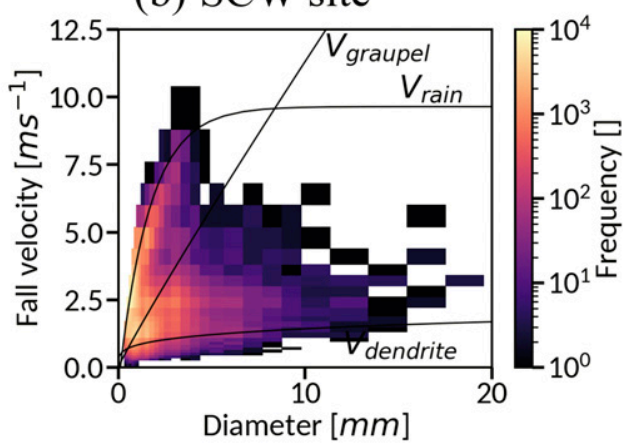

(d) GWU site

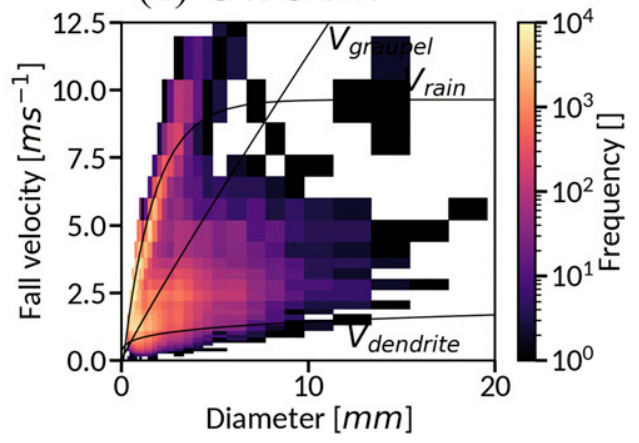

FIG. 9. As in Fig. 4, but from 1500 UTC 4 Mar to 0000 UTC 5 Mar 2018. The solid lines indicate the relationships between particle fall velocity and diameters for three hydrometeor types, rain, graupel, and dendrite.

cloud ice in both WDM6 and WSM6 for CASE 2. In a colder environment, Pimlt is inefficient compared to CASE 1 and does not contribute to the formation of cloud water. Psaci and Psaut are significant sinks for cloud ice and the main sources for snow. The various accretion processes (Piacr, Pgacr, Pracs, Pgaci, and Paacw) that take place between liquid-phase hydrometeors and solid-phase hydrometeors generate graupel. Although Pracs, Pgaci, and Paacw are also responsible for the generation of graupel for CASE 1 (Fig. 6), more efficient accretion processes over the mixed-phase regime between $0^{\circ}$ and $-40^{\circ} \mathrm{C}$ occur in CASE2. The extended cloud top allows for the coexistence of solid-phase and liquid-phase hydrometeors, which produces more graupel.

The net condensation from water vapor to cloud water occurs with WDM6 (Fig. 10d) due to the more humid environment in CASE2 than in CASE1. The total number of hydrometeors also increases in CASE2 (Figs. 4 and 8). Pgmlt and Psmlt are the main source of rain generation in WDM6 and WSM6 (Figs. 10e,j). Overall, the WSM6 shows similar results to WDM6 in the percentage of microphysics budgets for hydrometeors. As in CASE1, one notable difference between the two simulations is the enhanced accretion of snow (a) Cloud ice

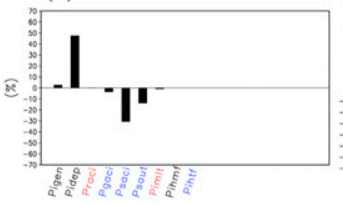

(f) Cloud ice

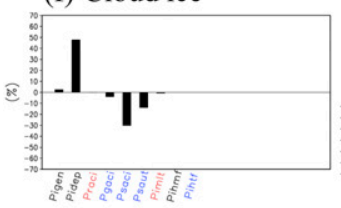

(b) Snow

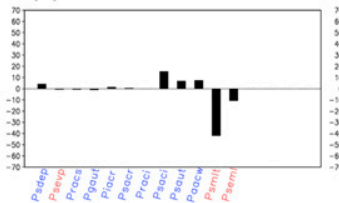

(g) Snow

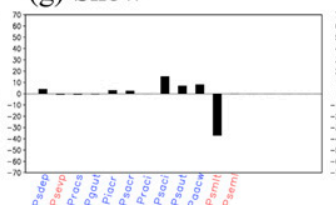

(c) Graupel

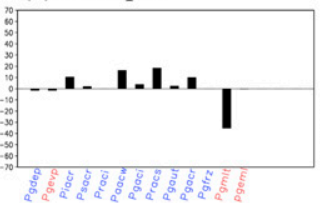

(h) Graupel

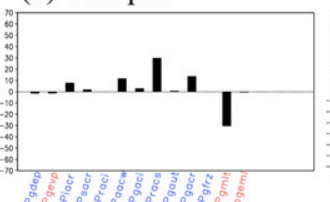

(d) Cloud water

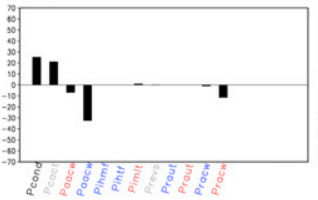

(i) Cloud water

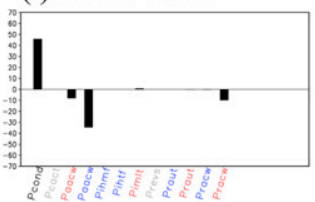

(e) Rain

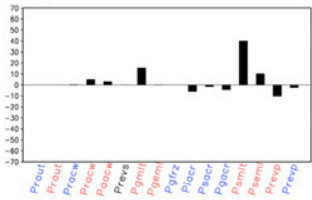

(j) Rain

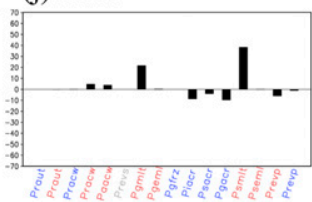

FIG. 10. As in Fig. 5, but representing CASE2. 
(a) WDM6_1.2 $\bar{V}_{I}$

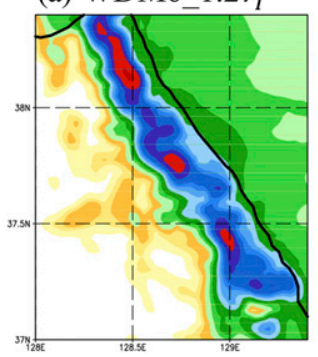

(e) WSM6_1.2 $\overline{V_{I}}$

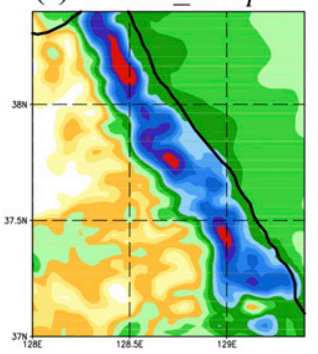

(b) WDM6_1.2 $\bar{V}_{I}-$ WDM6

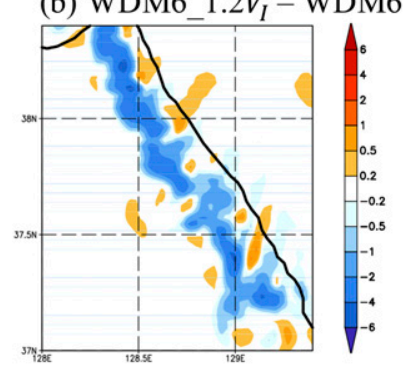

(f) WSM6_1.2 $\overline{V_{I}}-$ WSM6
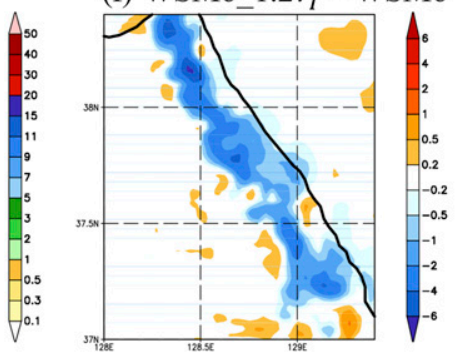

\section{(c)}

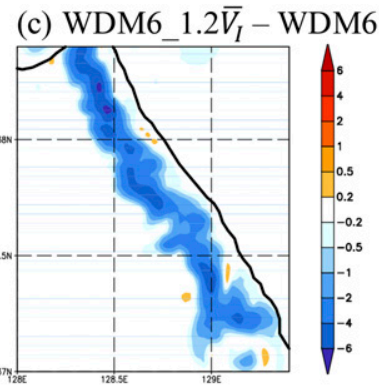

(g) WSM6_1.2 $\overline{V_{I}}-$ WSM6

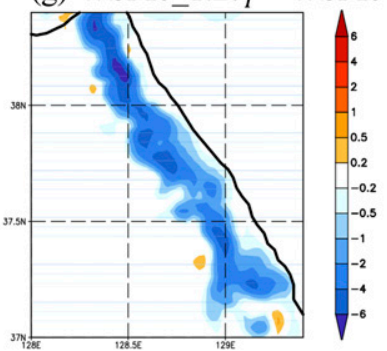

(d) WDM6_1.2 $\bar{V}_{I}-$ WDM6

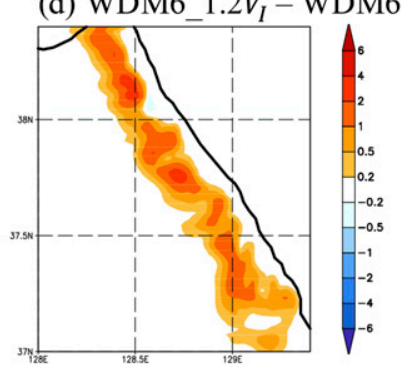

(h) WSM6_1.2 $\bar{V}_{I}-$ WSM6

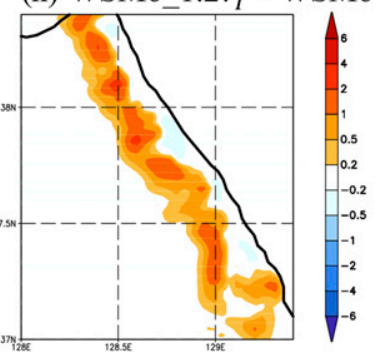

FIG. 11. (a) Simulated precipitation from WDM6_1.2 $\overline{V_{I}}$ for CASE1 and differences WDM6_1.2 $\overline{V_{I}}$ minus WDM6 in (b) simulated precipitation, (c) sum of surface snow and cloud ice, and (d) surface graupel. The units are all in millimeters (mm). (e)-(h) As in (a)-(d), but for WSM6_1.2 $\overline{V_{I}}$ and differences WSM6_1.2 $\overline{V_{I}}$ minus WSM6.

by rain (Pracs) in WSM6. The percentage of Pracs is higher in WSM6 than in WDM6, reducing the amount of snow and increasing graupel in WSM6. The reason for higher Pracs in WSM6 could be deduced from a smaller number of rain number concentrations having a larger size compared to WDM6 (Hong et al. 2010). This causes rain to fall quickly, thus enhancing Pracs in WSM6. Pracs is proportional to the relative difference of mass-weighted velocities between snow and rain.

In summary, a significant production of cloud ice generates an abundance of snow and graupel through the conversion from cloud ice to snow and the accretion of cloud water by snow/graupel. This leads to a significant positive bias in the surface precipitation amount for the shallow precipitation system. The snow amount at the surface primarily contributes to the total amount of surface precipitation. For the deep precipitation system, the depositional process also significantly contributes to the abundance of cloud ice. Several accretion processes between the liquid- and solid-phase hydrometeors efficiently generate graupel, resulting in less snow and more graupel at the surface. Therefore, surface precipitation is not significantly affected by the generation of cloud ice.

\section{c. Revisited formulation for the characteristics of cloud ice in WSM6 and WDM6}

The effect of the observational uncertainty of $\overline{V_{I}}$ on the simulated surface precipitation can be investigated from both WDM6_1.2 $\overline{V_{I}}$ and WSM6_1.2 $\overline{V_{I}}$ simulations. The spatial distribution feature of surface precipitation, including the location of maximum precipitation, does not change in WS(D)M6_ $1.2 \overline{V_{I}}$, compared to WS(D)M6, based on the comparisons between Figs. 11a and 3a, and Figs. 11a and 3b. However, the amount of surface precipitation is reduced in WDM6_1.2 $\overline{V_{I}}$ and WSM6_1.2 $\overline{V_{I}}$, compared to WDM6 and WSM6 (Figs. 11b,f) because of the reduction of snow at the surface (Figs. 11c,g). This alleviates the positive surface precipitation bias. Although the graupel amount at the surface increases in both WDM6_1.2 $\overline{V_{I}}$ and WSM6_1.2 $\overline{V_{I}}$ (Figs. 11d,h), the reduced amount of snow at the surface is greater than the amount of increased graupel, inducing the decrease in surface precipitation with a negligible difference in surface rain (not shown).

Figures $12 \mathrm{a}$ and $12 \mathrm{~b}$ for CASE1 show the differences in the vertical profiles of the time-domain-averaged mixing ratio between WDM6_1.2 $\overline{V_{I}}$ and WDM6, and between WSM6_1.2 $\overline{V_{I}}$ and WSM6. Reduced cloud ice and increased cloud water, except at the lower atmosphere below the $0.5-\mathrm{km}$ level, are found in the sensitivity experiments with both WDM6 and WSM6. The depositional process of cloud ice, depending on $N_{I}$, decreases due to reduced $N_{I}$ in both WDM6_1.2 $\overline{V_{I}}$ and WSM6_1.2 $\overline{V_{I}}$ (Figs. 13a,f), resulting in less cloud ice in WDM6_1.2 $\overline{V_{I}}$ and WSM6_1.2 $\overline{V_{I}}$. Less cloud ice reduces Psaci, Psaut, and Pimlt below the $1.5-\mathrm{km}$ layer. Although the sources of snow, such as Psaci and Psaut, are reduced, the amount of snow does not decrease above the $0.5-\mathrm{km}$ level due to the increase in Paacw and Psdep with the help of the increased cloud water and surplus water vapor amount. However, the reduced Psaci and Psaut near the surface contribute to the reduction in surface precipitation contributed by the snow. With decreased Pidep, redundant water vapor converts to cloud water through Pcact in WDM6 and Pcond in WSM6. Encased cloud water enhances Paacw. As Paacw is the most efficient process for generating graupel, the increased $\mathrm{Paacw}$ results in more graupel in both WDM6_1.2 $\overline{V_{I}}$ and WSM6_1.2 $\overline{V_{I}}$.

For CASE2, WDM6_1.2 $\overline{V_{I}}$ also shows reduced surface precipitation because of the decrease in surface snow relative 
(a) WDM6_1.2 $\bar{V}_{I}-$ WDM6

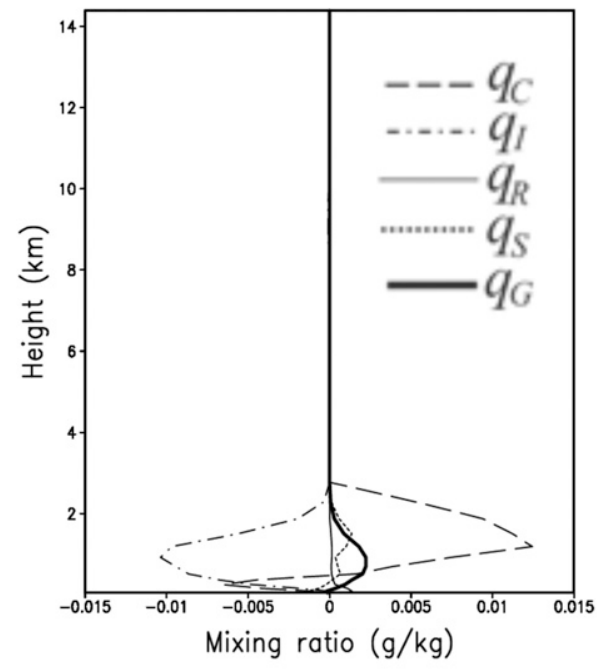

(c) WDM6_1.2 $\bar{V}_{I}-$ WDM6

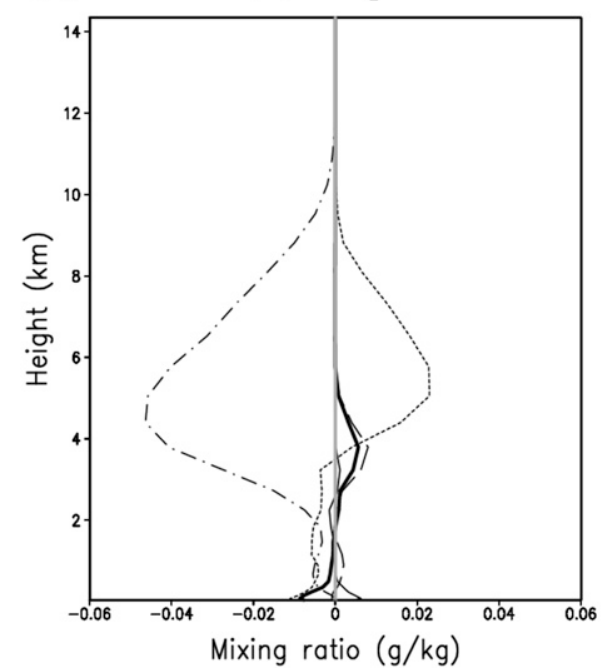

(b) WSM6_1.2 $\overline{V_{I}}-$ WSM6

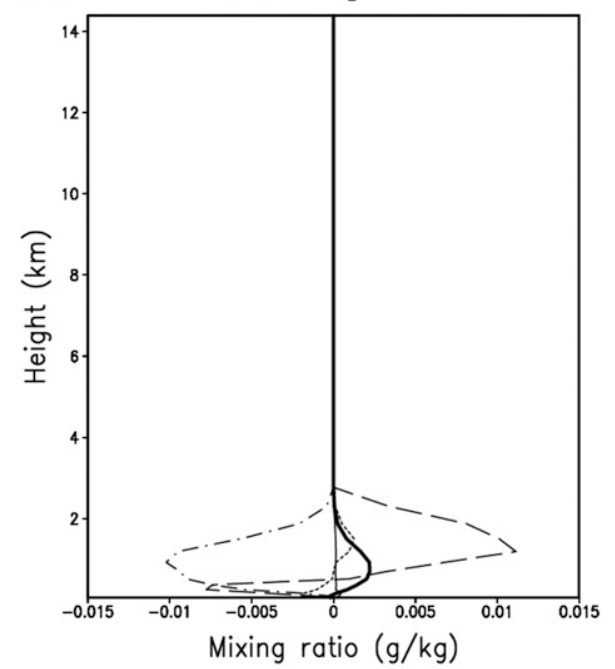

(d) WSM6_1.2 $\overline{V_{I}}-$ WSM6

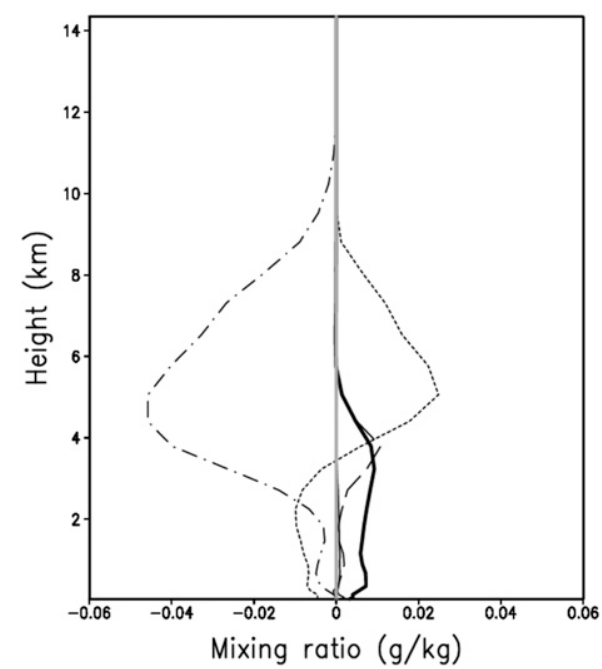

FIG. 12. Differences in vertical profiles of time-domain-averaged mixing ratios of hydrometeors for CASE1. (a) WDM6_1.2 $\overline{V_{I}}$ minus WDM6, and (b) WSM6_1.2 $\overline{V_{I}}$ minus WSM6. (c),(d) As in (a) and (b), but for CASE2.

to WDM6 (Figs. 14a-d), which is consistent with the results from CASE1. However, the reduced precipitation amount is less than the one for CASE1, while the increased $\overline{V_{I}}$ does not produce a distinct difference in surface precipitation in the WSM6 scheme. The amount of snow at the surface reduces, but the graupel amount at the surface increases and almost offsets the decreased surface amount of snow with WSM6 (Figs. 14e-h). The vertical profiles of hydrometeors show that cloud ice and snow below the 4-km level decrease, and that cloud water increases in both WDM6_1.2 $\overline{V_{I}}$ and WSM6_1.2 $\overline{V_{I}}$, as compared to WDM6 and WSM6 (Figs. 12c,d). Graupel in WSM6_1.2 $\overline{V_{I}}$ increases over the whole atmosphere, compared to WSM6.

Figures $15 \mathrm{a}$ and $15 \mathrm{f}$ show that Pidep decreases due to reduced $N_{I}$ in both WDM6_1.2 $\overline{V_{I}}$ and WSM6_1.2 $\overline{V_{I}}$, as in CASE1. The nucleation of cloud ice (Pigen) increases, which is caused by the increased initial mixing ratio of cloud ice in both simulations under enhanced $\overline{V_{I}}$. Psaut in the sensitivity experiment also increases because the threshold value for the autoconversion of ice crystals to snow decreases, thus converting more cloud ice into snow. The amount of snow increases with increased Psaut above the 4-km level. In Fig. 12c, the difference in the vertical profile of graupel between the control and sensitivity simulations with the WDM6 scheme is not significant, especially below the $2-\mathrm{km}$ level. The large reduction in the amount of graupel by Pgmlt offsets the increased graupel by Pracs and Paacw (Fig. 15c). However, the difference in Pgmlt between the control and sensitivity simulations with the WSM6 scheme is not distinct, so increased Pracs and Paacw produce more graupel in WSM6_1.2 $\overline{V_{I}}$ (Fig. 15h), inducing more graupel-type surface precipitation. In conclusion, the 
(a) cloud ice

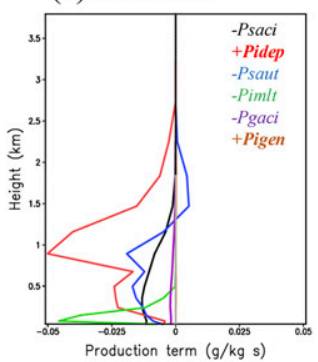

(f) cloud ice

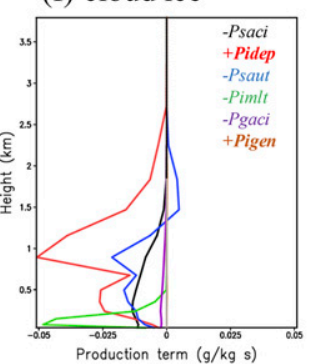

(b) snow

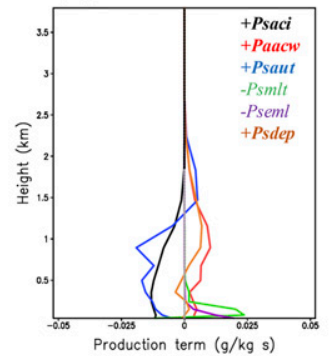

(g) snow

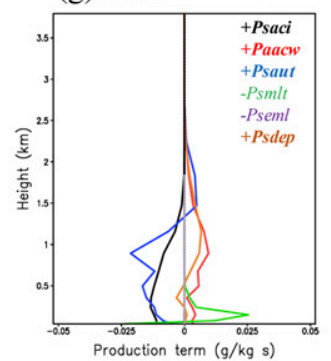

(c) graupel

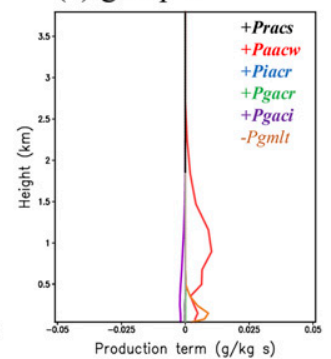

(h) graupel

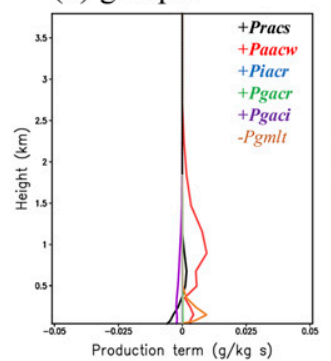

(d) Cloud water

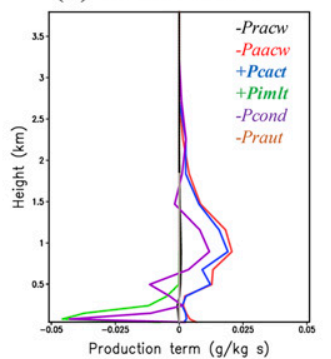

(i) Cloud water

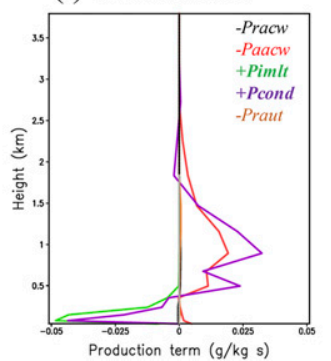

(e) Rain

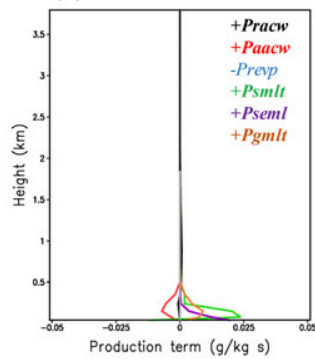

(j) Rain

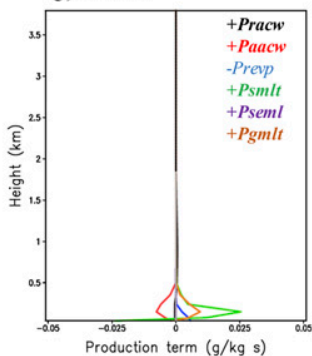

FIG. 13. Differences WDM6_1.2 $\overline{V_{I}}$ minus WDM6 in the vertical profiles of time-domain-averaged microphysics budgets for (a) cloud ice, (b) snow, (c) graupel, (d) cloud water, and (e) rain for CASE1. (f)-(j) As in (a)-(e), but for the differences of WSM6 runs (WSM6_1.2 $\overline{V_{I}}$ minus WSM6). The six main microphysics processes are represented for each hydrometeor. Here, all microphysics budgets are absolute values. A positive (or negative) sign process means the source (or sink) of hydrometeors.

different responses of the melting of graupel with the change in $\overline{V_{I}}$ in WDM6 and WSM6 induce the difference in response in simulated precipitation for CASE2.

\section{Summary}

This study evaluated the performance of four microphysics parameterizations, namely WDM6, WSM6, Morrison, and Thompson, in simulated surface precipitation over the mountainous region of the Republic of Korea during the ICE-POP 2018 field campaign. Two different snowstorm events were selected. The first event showed a relatively low cloud top at $\sim 3 \mathrm{~km}$ and produced weak precipitation intensity. The second event produced more precipitation than the first, and the cloud top was located approximately $12 \mathrm{~km}$. Both WDM6 and WSM6 (a) WDM6 $1.2 \bar{V}_{I}$

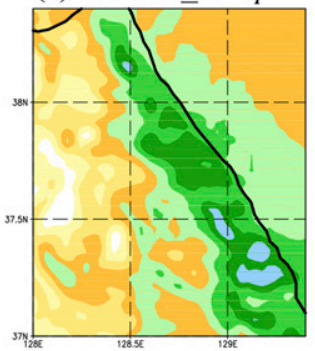

(e) WSM6_1.2 $\overline{V_{I}}$

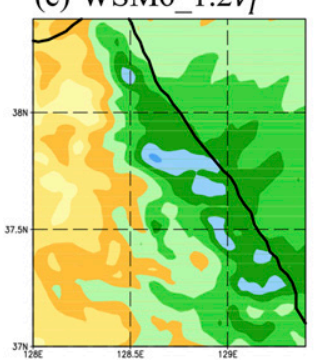

(b) WDM6_1.2 $\bar{V}_{I}-$ WDM6

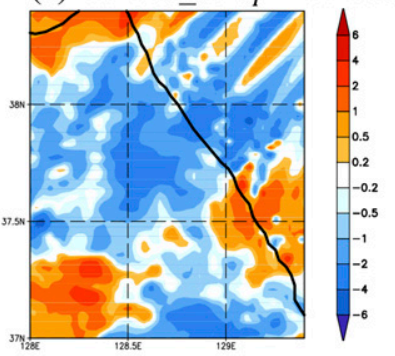

(f) WSM6_1.2 $\overline{V_{I}}-$ WSM6
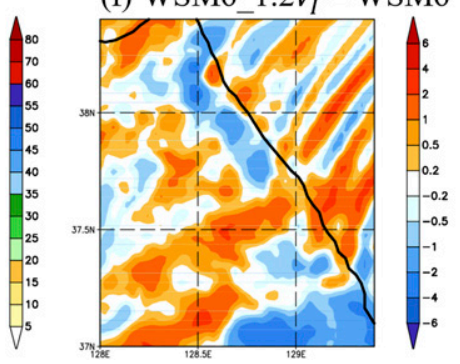

(c)
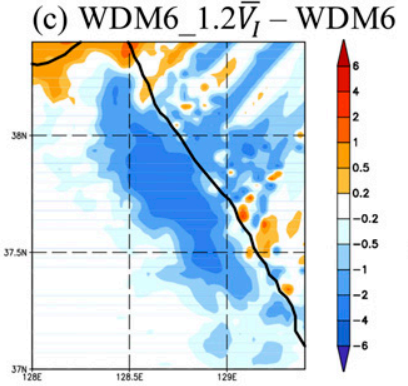

(d) WDM6 1.2 $\bar{V}_{I}-$ WDM6

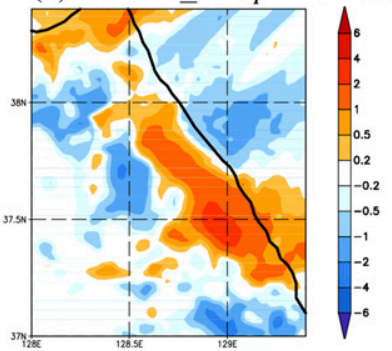

(g) WSM6_1.2 $\overline{V_{I}}-$ WSM6
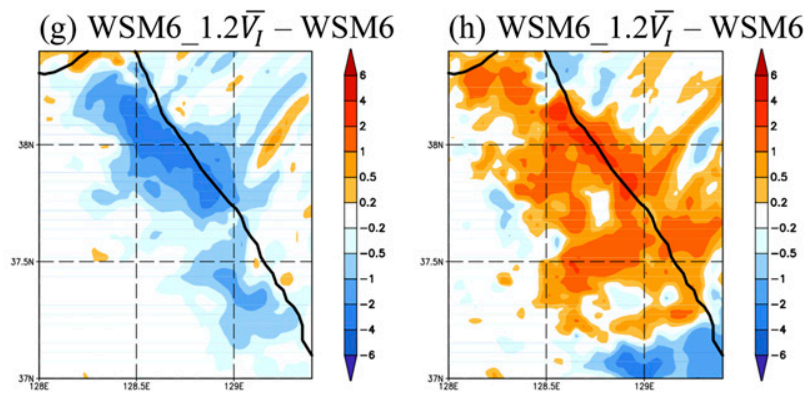

FIG. 14. As in Fig. 11, but representing CASE2. 
(a) cloud ice

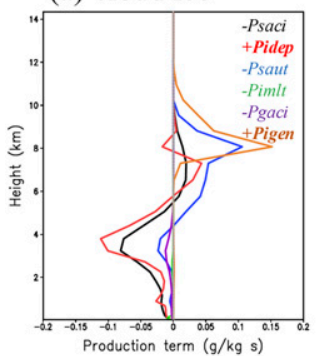

(f) cloud ice

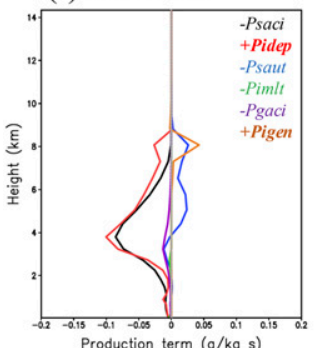

Production term ( $\mathrm{g} / \mathrm{kg} \mathrm{s})$ (b) snow

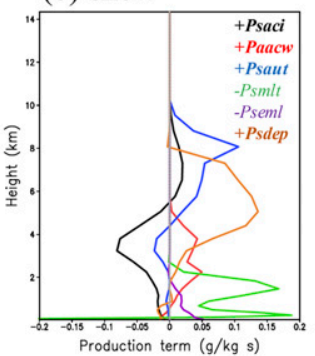

(g) snow

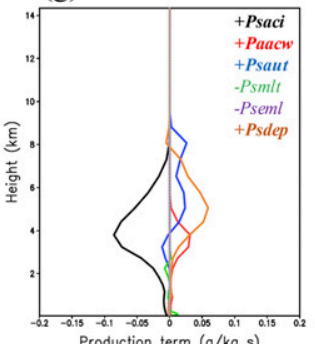

(c) graupel

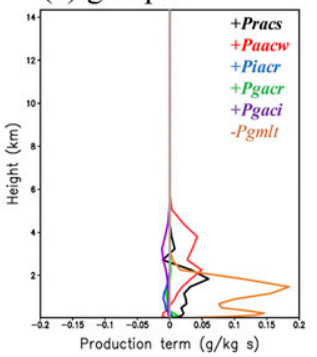

(h) graupel

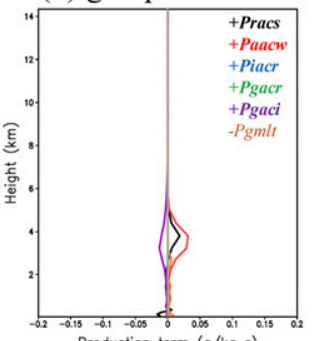

(d) Cloud water

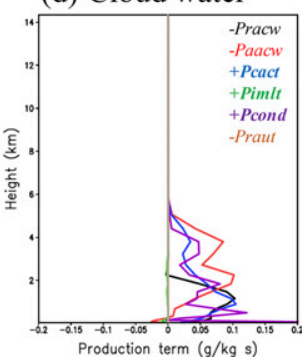

(i) Cloud water

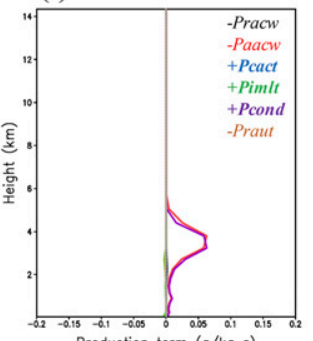

(e) Rain

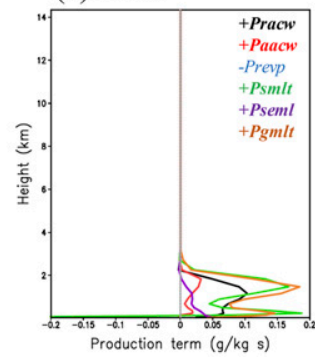

(j) Rain

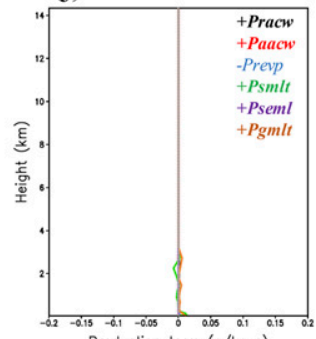

FIG. 15. As in Fig. 13, but representing CASE2.

overestimated the surface precipitation for the first case with low cloud tops because of the generation of cloud ice by the depositional process, which efficiently converted to snow and increased the surface precipitation contributed from the snow. Thompson also overestimated the surface precipitation, but the bias was lower than that of WSM6 and WDM6. Morrison showed the best agreement with the observation regarding the amount of surface precipitation and produced an insignificant amount of cloud ice and the least amount of snow at the surface.

For the second snow event featuring high cloud tops, both WDM6 and WSM6 produced a large amount of cloud ice. However, the other two schemes simulated a much lower amount of cloud ice, which did not affect the surface precipitation amount for this case. The analysis for the microphysics budget revealed that most of the cloud ice was generated by the depositional process, which was the same in the shallow snowstorm case. Enhanced mixed-phase cloud microphysics processes efficiently increased graupel and decreased snow. The greater amount of surface precipitation contributed by graupel was offset by the lower amount of surface precipitation contributed by snow in WDM6 and WSM6. Thompson and Morrison showed larger contributions of snow to the surface precipitation than WDM6 and WSM6. Overall, the differences in surface precipitation between the simulations were insignificant. Although the WDM6 and WSM6 showed positive bias in the simulated precipitation amount, both qualitatively concurred with the observation regarding the hydrometeor type at the surface.

The WDM6 and WSM6 share the same ice microphysics processes based on Hong et al. (2004). In both schemes, the cloud ice number concentration was diagnosed depending on the cloud ice mixing ratio. The relationship between the cloud ice number concentration and its mixing ratio is derived from the assumption that the mass-weighted terminal velocity of cloud ice $\overline{V_{I}}$, [Eq. (A3)] is equal to the individual velocity of cloud ice depending on cloud ice diameter [Eq. (A2)]. As the accuracy of $\overline{V_{I}}$ is $\pm 20 \%$ in both schemes, the number concentrations of cloud ice and ice microphysics processes are parameterized using a 1.2-times increase in $\overline{V_{I}}$.

The positive bias of the amount of surface precipitation was reduced by roughly $8 \%$ after applying the 1.2 -times increased $\overline{V_{I}}$ for the low cloud top storm case. This is because of the reduced depositional process and its subsequent effects on ice processes, such as the conversion of cloud ice into snow, and the accretion of cloud ice by snow with both WSM6 and WDM6 schemes. For the deep storm case, increasing $\overline{V_{I}}$ also reduced the ice deposition process, thus decreasing the amount of cloud ice. The WDM6 showed decreased surface precipitation with increasing $\overline{V_{I}}$, but WSM6 revealed no substantial decrease in signals. The effects of changing hydrometeor characteristics such as $\overline{V_{I}}$ on the simulated precipitation could vary, depending on the selected precipitation events and the cloud microphysics parameterizations used.

Acknowledgments. This work was supported by the Office of Science User Facility and the National Research Foundation of Korea (NRF) Grant 2019R1C1C1008482 funded by the South Korean government (MSIT), the Korea Meteorological Administration Research and Development Program under Grant KMI2018-06810, and the Korea Environmental Industry \& Technology Institute (KEITI) of the Korea Ministry of Environment (MOE) as "Advanced Water Management Research Program” (79615). Francisco J. Tapiador acknowledges the support from Projects CGL2016-78702 and PID2019-108470RB-C21 (FJT). The authors are greatly appreciative to the participants of the World Weather Research Programme Research Development Project and Forecast 
Demonstration Project, International Collaborative Experiments for Pyeongchang 2018 Olympic and Paralympic Winter Games (ICE-POP 2018), hosted by the Korea Meteorological Administration. We would like to thank KwangDeuk Ahn, YongHee Lee, and SangWon Joo from the Korea Meteorological Administration for their support during the field campaign.

\section{APPENDIX}

\section{Properties of Cloud Ice in WSM6 and WDM6}

In this appendix, the properties of cloud ice in WSM6 and WDM6 are summarized, which is originally from Hong et al. (2004). The individual crystal is assumed as a single bullet, following Heymsfield and Iaquinta (2000). The mass-diameter and fall speed-diameter relations for the individual crystal are expressed by Eqs. (A1) and (A2):

$$
\begin{aligned}
D_{I}(\mathrm{~m}) & =11.9\left(M_{I}\right)^{0.5}, \\
V_{I}\left(\mathrm{~m} \mathrm{~s}^{-1}\right) & =1.49 \times 10^{4}\left(D_{I}\right)^{1.31} .
\end{aligned}
$$

In these equations, the terms $M_{I}$ and $D_{I}$ are in kilograms and meters, respectively. The mean mass-weighted terminal velocity of falling cloud ice $\overline{V_{I}}$ can be expressed as a function of $\rho_{a} q_{I}$ that follows the method by Heymsfield and Donner (1990):

$$
\overline{V_{I}}\left(\mathrm{~m} \mathrm{~s}^{-1}\right)=3.29\left(\rho_{a} q_{I}\right)^{0.16}
$$

Here, $\rho_{a}$ and $q_{I}$ represent the dry air density and the cloud ice mixing ratio. Hong et al. (2004) assume that $\overline{V_{I}}$ in Eq. (A3) is consistent with the individual crystal fall speed $V_{I}$ in Eq. (A2). This could be possible when the mean size of all cloud ice in a grid box is same and there is no assumption of size distribution associated with cloud ice number concentration. From this assumption, $\rho_{a} q_{I}$ can be expressed as $D_{I}$, which is shown in Eq. (A4):

$$
3.29\left(\rho_{a} q_{I}\right)^{0.16}=1.49 \times 10^{4}\left(D_{I}\right)^{1.31} .
$$

By using Eq. (A1) and the mean mass of ice crystal, $M_{I}=$ $\rho_{a} q_{I} / N_{I}$, Eq. (A4) can be written as

$$
N_{I}\left(\mathrm{~m}^{-3}\right)=5.38 \times 10^{7}\left(\rho_{a} q_{I}\right)^{0.75} .
$$

Both WSM6 and WDM6 applied the cloud ice number concentration $N_{I}$, which depends on the cloud ice mass shown in Eq. (A5), based on the study of Hong et al. (2004). By rearranging Eq. (A5), we can express cloud ice mass as a function of $N_{I}$, as in Eq. (A6a):

$$
\rho_{a} q_{I}\left(\mathrm{~kg} \mathrm{~m}^{-3}\right)=4.92 \times 10^{-11} N_{I}^{1.33} .
$$

By applying Eq. (A1) and the mean mass of ice crystal, $M_{I}=$ $\rho_{a} q_{I} / N_{I}$, into Eq. (A6a), $\rho_{a} q_{I}$ can be expressed as a function of $D_{I}$, as in Eq. (A6b):

$$
\rho_{a} q_{I}\left(\mathrm{~kg} \mathrm{~m}^{-3}\right)=2.08 \times 10^{22} D_{I}^{8} .
$$

Equations (A5) and (A6a) are same as Eqs. (5c) and (5d) of Hong et al. (2004).

\section{REFERENCES}

Atlas, D., R. C. Srivastava, and R. S. Sekhon, 1973: Doppler radar characteristics of precipitation at vertical incidence. Rev. Geophys., 11, 1-35, https://doi.org/10.1029/RG011i001p00001.

Bae, S., S.-Y. Hong, and K.-S. S. Lim, 2016: Coupling WRF doublemoment 6-class microphysics schemes to RRTMG radiation scheme in Weather Research Forecasting model. Adv. Meteor., 2016, 5070154, https://doi.org/10.1155/2016/5070154.

Benjamin, S. G., J. M. Brown, and T. G. Smirnova, 2016: Explicit precipitation-type diagnosis from a model using a mixed-phase bulk cloud-precipitation microphysics parameterizations. Wea. Forecasting, 31, 609-619, https://doi.org/10.1175/WAFD-15-0136.1.

Burg, T., K. L. Elmore, and H. M. Grams, 2017: Assessing the skill of updated precipitation type diagnostics for the Rapid Refresh with mPING. Wea. Forecasting, 32, 725-732, https:// doi.org/10.1175/WAF-D-16-0132.1.

Byun, U.-Y., J. Hong, S.-Y. Hong, and H. H. Shin, 2015: Numerical simulations of heavy rainfall over central Korea on 21 September 2010 using the WRF model. Adv. Atmos. Sci., 32, 855-869, https:// doi.org/10.1007/s00376-014-4075-6.

Campbell, L. S., W. J. Steenburgh, Y. Yamada, M. Kawashima, and Y. Fujiyoshi, 2018: Influences of orography and coastal geometry on a transverse-mode sea-effect snowstorm over Hokkaido Island, Japan. Mon. Wea. Rev., 146, 2201-2220, https://doi.org/10.1175/ MWR-D-17-0286.1.

Chen, F., and J. Dudhia, 2001: Coupling and advanced land surface- hydrology model with the Penn State-NCAR MM5 modeling system. Part I: Model implementation and sensitivity. Mon. Wea. Rev., 129, 569-585, https://doi.org/10.1175/ 1520-0493(2001)129<0569:CAALSH > 2.0.CO;2.

Cheong, S.-H., K.-Y. Byun, and T.-Y. Lee, 2006: Classification of snowfalls over the Korean peninsula based on developing mechanism. Atmosphere, 16, 33-48.

Comin, A. N., V. Schumacher, F. Justino, and A. Fernández, 2018: Impact of different microphysical parameterizations on extreme snowfall events in the Southern Andes. Wea. Climate Extremes, 21, 65-75, https://doi.org/10.1016/j.wace.2018.07.001.

Conrick, R., and C. F. Mass, 2019: An evaluation of simulated precipitation characteristics during OLYMPEX. J. Hydrometeor., 20, 1147-1164, https://doi.org/10.1175/JHM-D-18-0144.1.

Dee, D. P., and Coauthors, 2011: The ERA-Interim reanalysis: Configuration and performance of the data assimilation system. Quart. J. Roy. Meteor. Soc., 137, 553-597, https://doi.org/ 10.1002/qj.828.

Gunn, R., and G. D. Kinzer, 1949: The terminal velocity of fall for water droplets in stagnant air. J. Meteor., 6, 243-248, https:// doi.org/10.1175/1520-0469(1949)006<0243:TTVOFF>2.0.CO;2.

Han, M., S. A. Braun, T. Matsui, and C. R. Williams, 2013: Evaluation of cloud microphysics schemes in simulations of a winter storm using radar and radiometer measurements. J. Geophys. Res. Atmos., 118, 1401-1419, https://doi.org/10.1002/ JGRD.50115.

Heymsfield, A. J., and L. J. Donner, 1990: A scheme for parameterizing ice-cloud water content in general circulation models. J. Atmos. Sci., 47, 1865-1877, https://doi.org/10.1175/15200469(1990)047<1865:ASFPIC > 2.0.CO;2.

—_, and J. Iaquinta, 2000: Cirrus crystal terminal velocities. J. Atmos. Sci., 57, 916-938, https://doi.org/10.1175/15200469(2000)057<0916:CCTV>2.0.CO;2.

Hong, S.-Y., and J.-O. J. Lim, 2006: The WRF Single-Moment 6-class microphysics scheme (WSM6). J. Korean Meteor. Soc., 42, 129-151. 
J. Dudhia, and S.-H. Chen, 2004: A revised approach to ice microphysical processes for the bulk parameterization of clouds and precipitation. Mon. Wea. Rev., 132, 103-120, https://doi.org/ 10.1175/1520-0493(2004)132<0103:ARATIM>2.0.CO;2.

—, Y. Noh, and J. Dudhia, 2006: A new vertical diffusion package with an explicit treatment of entrainment processes. Mon. Wea. Rev., 134, 2318-2341, https://doi.org/10.1175/MWR3199.1.

—_, K.-S. S. Lim, Y.-H. Lee, J.-C. Ha, H.-W. Kim, and S.-J. Ham, 2010: Evaluation of the WRF double-moment 6-class microphysics scheme for precipitating convection. Adv. Meteor., 2010, 707253, https://doi.org/10.1155/2010/707253.

Iacono, M. J., J. S. Delamere, E. J. Mlawer, M. W. Shephard, S. A. Clough, and W. D. Collins, 2008: Radiative forcing by longlived greenhouse gases: Calculations with the AER radiative transfer models. J. Geophys. Res., 113, D13103, https://doi.org/ 10.1029/2008JD009944.

Ikeda, K., M. Steiner, J. Pinto, and C. Alexander, 2013: Evaluation of cold-season precipitation forecasts generated by the hourly updating High-Resolution Rapid Refresh model. Wea. Forecasting, 28, 921-939, https://doi.org/10.1175/WAF-D-12-00085.1.

Kain, J. S., 2004: The Kain-Fritsch convective parameterization: An update. J. Appl. Meteor., 43, 170-181, https://doi.org/ 10.1175/1520-0450(2004)043<0170:TKCPAU>2.0.CO;2.

—_, and J. M. Fritsch, 1990: A one-dimensional entraining/ detraining plume model and its application in convective parameterization. J. Atmos. Sci., 47, 2784-2802, https://doi.org/ 10.1175/1520-0469(1990)047<2784:AODEPM>2.0.CO;2.

Laird, N. F., J. E. Walsh, and D. A. R. Kristovich, 2003: Model simulations examining the relationships of lake-effect morphology to lake shape, wind direction, and wind speed. Mon. Wea. Rev., 131, 2102-2111, https://doi.org/10.1175/1520-0493(2003)131<2102: MSETRO $>2.0 . \mathrm{CO} ; 2$.

Lee, J.-E., S.-H. Jung, H.-M. Park, S. Kwon, P.-L. Lin, and G. Lee, 2015: Classification of precipitation types using fall velocitydiameter relationships from 2D-video distrometer measurements. Adv. Atmos. Sci., 32, 1277-1290, https://doi.org/10.1007/ s00376-015-4234-4.

Lim, K.-S. S., and S.-Y. Hong, 2010: Development of an effective double-moment cloud microphysics scheme with prognostic cloud condensation nuclei $(\mathrm{CCN})$ for weather and climate models. Mon. Wea. Rev., 138, 1587-1612, https://doi.org/10.1175/ 2009MWR2968.1.

_ - J.-M. Lim, H. H. Shin, J. Hong, Y.-Y. Ji, and W. Lee, 2019: Impacts of subgrid-scale orography parameterization on simulated atmospheric fields over Korea using a high-resolution atmospheric forecast model. Meteor. Atmos. Phys., 131, 975985, https://doi.org/10.1007/s00703-018-0615-4.

Liu, C., K. Ikeda, G. Thompson, R. M. Rasmussen, and J. Dudhia, 2011: High-resolution simulations of wintertime precipitation in the Colorado Headwaters region: Sensitivity to physics parameterizations. Mon. Wea. Rev., 139, 3533-3553, https:// doi.org/10.1175/MWR-D-11-00009.1.

Löffler-Mang, M., and J. Joss, 2000: An optical disdrometer for measuring size and velocity of hydrometeors. J. Atmos. Oceanic Technol., 17, 130-139, https://doi.org/10.1175/15200426(2000)017<0130:AODFMS>2.0.CO;2.

McMillen, J. D., and W. J. Steenburgh, 2015: Impact of microphysics parameterizations on simulations of the 27 October 2010 Great Salt Lake-effect snowstorm. Wea. Forecasting, 30, 136-152, https://doi.org/10.1175/WAF-D-14-00060.1.

Min, K. H., S. Choo, D. Lee, and G. Lee, 2015: Evaluation of WRF cloud microphysics schemes using radar observations. Wea. Forecasting, 30, 1571-1589, https://doi.org/10.1175/WAF-D14-00095.1.

Morcrette, J. J., H. W. Barker, J. N. S. Cole, M. J. Iacono, and R. Pincus, 2008: Impact of a new radiation package, McRad, in the ECMWF integrated forecasting system. Mon. Wea. Rev., 136, 4773-4798, https://doi.org/10.1175/2008MWR2363.1.

Morrison, H., J. A. Curry, and V. I. Khvorostyanov, 2005: A new double-moment microphysics parameterization for application in cloud and climate models. Part I: Description. J. Atmos. Sci., 62, 1665-1677, https://doi.org/10.1175/JAS3446.1.

_ J. A. Milbrandt, G. H. Bryan, K. Ikeda, S. A. Tessendorf, and G. Thompson, 2015: Parameterization of cloud microphysics based on the prediction of bulk ice particle properties. Part II: Case study comparisons with observations and other schemes. J. Atmos. Sci., 72, 312-339, https://doi.org/10.1175/JAS-D-140066.1 .

Skamarock, W. C., and Coauthors, 2008: A description of the Advanced Research WRF version 3. NCAR Tech. Note NCAR/ TN-475+STR, 113 pp., https://doi.org/10.5065/D68S4MVH.

Song, H.-J., and B. J. Sohn, 2018: An evaluation of WRF microphysics schemes for simulating the warm-type heavy rain over the Korean peninsula. Asia-Pac. J. Atmos. Sci., 54, 225-236, https://doi.org/10.1007/S13143-018-0006-2.

Thompson, G., P. R. Field, R. M. Rasmussen, and W. D. Hall, 2008: Explicit forecasts of winter precipitation using an improved bulk microphysics scheme. Part II: Implementation of a new snow parameterization. Mon. Wea. Rev., 136, 5095-5115, https://doi.org/10.1175/2008MWR2387.1.

Tokay, A., D. B. Wolff, and W. A. Petersen, 2014: Evaluation of the new version of the laser-optical disdrometer, OTT parsivel. J. Atmos. Oceanic Technol., 31, 1276-1288, https://doi.org/ 10.1175/JTECH-D-13-00174.1.

Yeo, N., and E.-C. Chang, 2018: Impact of the land-sea temperature contrast on the snowfall structure over the western coastal region of the Korean Peninsula. Asia-Pac. J. Atmos. Sci., 54, 253-263, https://doi.org/10.1007/S13143-018-0011-5. 